UNIVERSITÀ CATTOLICA DEL SACRO CUORE

Dipartimento di Economia e Finanza

\author{
Working Paper Series
}

Is it the way you live or the job you have?

Health effects of lifestyles and working conditions

Elena Cottini, Paolo Ghinetti

Working Paper n. 56

March 2017

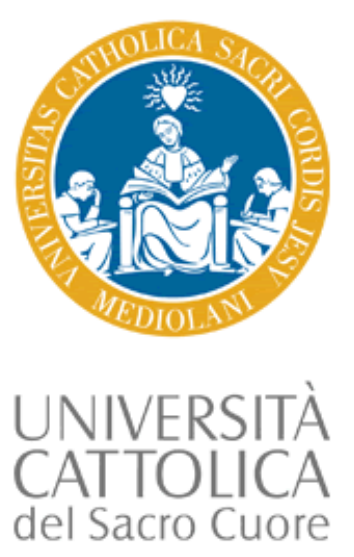




\title{
Is it the way you live or the job you have? Health effects of lifestyles and working conditions
}

\author{
Elena Cottini \\ Università Cattolica del Sacro Cuore \\ Paolo Ghinetti \\ Università degli studi del Piemonte Orientale
}

Working Paper n. 56

March 2017

\author{
Dipartimento di Economia e Finanza \\ Università Cattolica del Sacro Cuore \\ Largo Gemelli 1 - 20123 Milano - Italy \\ tel: +39.02.7234.2976 - fax: +39.02.7234.2781 \\ e-mail: dip.economiaefinanza@unicatt.it
}

The Working Paper Series promotes the circulation of research results produced by the members and affiliates of the Dipartimento di Economia e Finanza, with the aim of encouraging their dissemination and discussion. Results may be in a preliminary or advanced stage. The Dipartimento di Economia e Finanza is part of the Dipartimenti e Istituti di Scienze Economiche (DISCE) of the Università Cattolica del Sacro Cuore. 


\title{
Is it the way you live or the job you have? \\ Health effects of lifestyles and working conditions
}

\author{
Elena Cottini ${ }^{*}$ and Paolo Ghinetti ${ }^{* *}$
}

\begin{abstract}
This paper investigates the role of lifestyles (smoking, drinking and obesity) and working conditions (physical hazards, no support from colleagues, job worries and repetitive work) on health. Three alternative systems of simultaneous multivariate probit equations are estimated, one for each health measure: an indicator of self-assessed health, an indicator of physical health, an indicator of work-related mental health problems, using Danish data for 2000 and 2005. We find that while lifestyles are significant determinants of self-assessed health, they play a minor role for our indicators of physical health and mental health. The effect of lifestyles seems to be dominated by the effect of adverse working conditions, which significantly worsen health. This result is robust for all health dimensions considered.
\end{abstract}

\footnotetext{
* Dipartimento di Economia e Finanza, Università Cattolica del S. Cuore, via Necchi 5, 20123 Milano, Italy email:elena.cottini@unicatt.it. and Centre for Corporate Performance, Copenaghen Business School, Porcelænshaven 18A/B, 2000 Frederiksberg, Denmark.

** Corresponding author. Dipartimento di Studi per l'Economia e l'Impresa, Università del Piemonte Orientale, via Perrone 18, 28100 Novara, Italy. email: paolo.ghinetti@uniupo.it.
} 


\section{Introduction}

Individuals' health is affected by several factors related to both work and non-work activities. Among the latter, good lifestyle practices attracted growing attention. Unhealthy behaviours, i.e., smoking, heavy drinking, bad food habits, physical inactivity, and related risk factors such as obesity are key determinants of major preventable diseases, with high economic and social costs. According to WHO estimates, up to $80 \%$ of cases of coronary heart disease, $90 \%$ of type 2 diabetes cases, and one-third of cancers can be avoided by adopting healthier lifestyles and quitting smoking (World Health Organisation, 2008).

In this perspective, the EU calls for a better understanding of how health and emerging risks, such as for example psychosocial working conditions are actually connected at the workplace level. For example, the European Commission has recognised job quality as a key ingredient of the European Employment Strategy (EU, 2001). New sources of health stressors are gaining importance. The period of rapid transformation in the organisation of the production system, has promoted a shift from manual occupations to others with a prevalence of soft and intellectual tasks. As a result, the traditional sources of adverse physical working conditions are declining, whereas the share of workers subject to psychosocial job stressors is increasing (Cappelli et al., 1997, OECD 2008). More research on these issues is important because inadequate working conditions negatively affect health, with costly consequences both for individuals and for the society at large. At a broad level, the social costs of mental health have been estimated to be as high as $3 \%$ to 4 $\%$ of GDP in the European Union (International Labour Organization).

This paper contributes to the literature on the determinants of health outcomes in two respects. First, we consider the joint effect of lifestyles and work conditions in this context and we also account for their correlation through unobservables. This is important to gauge their genuine effect on health outcomes which otherwise would suffer from an omitted variable bias. Although the relevance of accounting for both simultaneously seems apparent, it has been widely neglected in the literature. Second, we expand the analysis in terms of health outcomes considering, in addition to a standard measure of self-assessed health also physical and mental health. This is important to take into account the multidimensional nature of health and to provide additional insight on the complex interplay between risky behaviours, hazardous work conditions and specific health 
indicators. Evidence on that may provide insights into how to limit work and non-work related causes of health decline.

To this purpose we use a unique dataset for Denmark, obtained matching the 2000 and 2005 waves of the Danish Work Environment Cohort Study (DWECS) with administrative data from the Statistics Denmark Integrated Labour Market Database (IDA) The resulting dataset provides information on all our dimensions of interest: lifestyles, work conditions and health outcomes. From a policy perspective, Denmark is an interesting country: in recent years the European recommendations in terms of health and safety at work have been implemented by the National Working Environment Authority through a set of guidelines to improve working conditions and screen enterprises in a systematic manner.

Our findings from simple probits show that bad lifestyles and adverse working conditions have a negative association with self-assessed health, physical health indicators and mental health. However, multivariate probit estimates - that account for the endogeneity of working conditions and lifestyles - show that working conditions always play a substantial role in affecting whatever measure of health. On the contrary, a modest net impact is found for lifestyles on physical health and mental health while effects are maintained on self-assessed health.

The remainder of the paper is organised as follows. In Section 2 we review the relevant literature, while the data are overviewed in Section 3. In Section 4 we present our empirical model sand in Section 5 we present the main results. Section 6 concludes.

\section{Related literature}

The relationship between lifestyles and health has received considerable attention by epidemiologists (Breslow 1999, Hu et al. 2005; Patja et al. 2005 among others) and in the areas of medicine and occupational health (Netterstrøm et al. 1991; Hellerstedt and Jeffery 1997; Otten, Bosma and Swinkels 1999; Siegrist and Rödel 2006; Borg and Kristensen, 2000). In economic terms, individual's health is typically considered as a multifaceted good having both consumption and capital components, which is produced over time by means of individual choices and which depends on environmental determinants (Contoyannis and Jones, 2004). In particular, we may think at health as affected by both work-related and 
non-work related determinants. Nevertheless, general health is only one aspect of health status and other health indicators must be used to take into account the multidimensional nature of health (Loprest et al., 1995).

Within the economics literature, a pioneer in analysing the role of non-work related determinants in a health production framework is Kenkel (1995). The author finds that health is significantly affected by several lifestyles such as diet, smoking, exercise, alcohol consumption, good sleep, weight (relative to height) and stress. Other have focused on single behaviours such as smoking (see, e.g., Blaylock and Blisard, 1992 and Mully and Portney, 1990) or have examined interactions between lifestyle (see, e.g., Hu et al., 1995).

Balia and Jones (2008) investigate the determinants of premature mortality in Great Britain and the contribution of lifestyle choices to socio-economic inequality in mortality. They use a maximum simulated likelihood approach for a multivariate probit to estimate a recursive system of equations for mortality, morbidity and lifestyles. The analysis shows that, after allowing for endogeneity, lifestyles contribute strongly to inequality in mortality, reducing the direct role of socio-economic status.

Contoyannis and Jones (2004) estimate the structural parameters of a health production function, together with the reduced form parameters for six lifestyle equations using panel data from the Health and Lifestyle Survey conducted in the United Kingdom in 1984 and 1991. They use Maximum Simulated Likelihood for a multivariate probit model with discrete indicators of lifestyle choices and self-assessed health. They find a reduction in the influence of socioeconomic characteristics on health once lifestyles are included in the model. In particular sleeping well, exercising, and not smoking in 1984 have dramatic positive effects on the probability of reporting excellent or good health in 1991. Moreover, these effects are shown to be larger once the endogeneity of lifestyles is accounted for. We extend this framework by including adverse working conditions (together with lifestyles) and two additional health dimensions.

On the work-related variables side, Robone et al. (2011) use the BHPS data to analyse whether health is hampered by adverse working and by contractual conditions. They distinguish between self-assessed health and psychological well-being. The working conditions variables considered are shift work, overtime, to be a union member, supervision, job satisfaction, which are only proxies of the more accurate conceptual 
categories developed by the literature. They find that being unsatisfied with working hours is negatively related with health, especially in the case of part-time jobs. Having low expectations about future career advancements reduces the health of temporary workers.

Datta Gupta and Kristensen (2008) use ECHP panel data for Denmark, France and Spain to detect a causal relationship between work environment indicators and general versus work related self-assessed health. Their proxy for working conditions is a single variable for individual satisfaction with the work environment. Moreover, the authors cannot distinguish between mental and physical health. In this context, a separate analysis of the determinants of physical and mental health seems particularly relevant, especially for policy purposes.

A series of studies analyse the link between working conditions and different dimensions of health across countries using the European Working Conditions Survey. Overall they show that adverse working conditions, in terms of psychological job demands and physical hazards are strongly associated to workers' mental health conditions, supporting the widely debated perception that adverse working conditions may harm workers' mental health (Cottini and Lucifora, 2013; Cottini 2012, among others).

The study that is most similar to ours is Borg and Kristensen (2000), who using the 1990 and 1995 waves from the Danish Work Environment Cohort Study describe differences in work environment and lifestyle factors between social classes in Denmark and investigate if these factors explain social class differences in terms of changes in selfrated health. The authors construct seven scales of indicators describing psychosocial conditions, four scales of physical hazards and two indicators of lifestyles. They find higher prevalence in the lower social classes of repetitive work, low skill discretion, low influence at work, high job insecurity and physical hazards. High psychological demands and conflicts at work were more prevalent in the higher social classes. With regard to lifestyles, they found that obese people and smokers are more prevalent among the lower classes.

They use the same survey as us, but we differentiate from them, first, by estimating a richer and flexible empirical model, which takes advantage of the information available at the individual level to model the endogeneity of lifestyle and working conditions. Second, by distinguishing between self-assessed, physical and mental health. Third, by focussing on a narrower set of working conditions, due to limits imposed by data availability and 
empirical model's tractability.

\section{Data and variables}

The data we use derive from two different sources matched through individual identifiers. First is a panel collected every 5 years by the Institute for Occupational Health (AMI), The Danish Work Environment Cohort Study (DWECS). The questionnaire contains detailed work environment information together with occupational, health outcomes and lifestyle information. For the purpose of the paper we focus on 2000 and 2005 since for these are the two waves for which we can define a wider and comparable set of health outcomes.

Second we use Statistics Denmark Integrated Labour Market Database (IDA), which includes the Danish population of individual and establishment administrative records together with background characteristics. Danish administrative registers record individual annual earnings as well as demographic and firm characteristics. Even though IDA comprises the whole population of Danish firms and workers, when matched to DWECS we end up with 3,000 observations for each wave.

We measure health is three different ways. The first is an indicator of self-assessed health $(S A H) .{ }^{1}$ Respondents were asked to rank their health status which takes one of five values ranging from very good to very poor (the question asked is: "How will you overall evaluate your health: 1. Very good, 2. Good, 3. Fair, 4. Poor, 5. Very poor"). We transformed the categorical indicator of $S A H$ into a binary variable that takes value 1 if individual perceived health is excellent or good, and 0 if it is fair or poor. This is of course a general measure of individuals' health and subject to well-known conceptual problems. However, it represents one of the mostly used indicator in the literature (see Datta Gupta and Kristensen (2007) for a discussion about the limitations in the use of $S A H$ ).

The second indicator is a measure of physical health $(P H)$. It is constructed using a set of questions on specific objective symptoms related to physical problems. Literally, the questions asks: "Have you felt pain in the last twelve months (for more than 30 days) in the..? (i) neck; (ii) knees; (iii) shoulder; (iv) hand; (v) low back?". For each of these

\footnotetext{
${ }^{1}$ Many studies have demonstrated that self-reported measures of health are a powerful predictor for mortality, also after control for other measures of health such as medical diagnoses or functional ability (e.g. Idler and Benyamini, 1997). Of course, this measure is not perfect although widely used. For example, Jurges (2008) shows evidence that self-reported health status is sometimes answered in a relative sense.
} 
symptoms a dummy variable was created $(P H)$ equal to 0 if the individual experienced at least one of these symptoms and value 1 otherwise.

The third indicator we use is $M H$ which captures a series of emotional and moodrelated problems reported by the worker as being work-related. This indicator is constructed using the following questions: "How much of your working hours during the last month you felt..? (i) nervous, (ii) down and nothing could cheer you up, (iii) blue",2. Out of the above responses we specified a set of dummies that take value 1 if the worker answers that often/most of the time experiences those symptoms, 0 if not. The $M H$ variable is a dummy taking value 0 for at least one of the morbidity variables taking value 1 , and taking value 1 otherwise.

Note that all our dependent variables take the value 1 in case of "good health" reported by the individual. ${ }^{3}$ Further, $P H$ is rather specific as it captures that physical health related to musculoskeletal diseases, which is highly relevant in our context since over 40 million workers in Europe are affected by musculoskeletal diseases (MSDs) attributable to their work. ${ }^{4}$

The demand-control model of Karasek and Theorell (1990) and the effort-reward model of Siegrist (1996) provide a standard conceptual guidance for the definition of the variables describing adverse working conditions $(W C) .{ }^{5}$ According to this framework, three

\footnotetext{
${ }^{2}$ It should be noted that this set of indicators can be considered as a first order approximation to the widely used DSM-IV classification for psychiatric diseases Goldberg et al. (1997).

${ }^{3}$ The way we use to aggregate the symptoms into $\mathrm{MH}$ and PH variables is somehow arbitrary. In principle, synthetic indicators like $\mathrm{MH}$ and $\mathrm{PH}$ are less informative but more empirically tractable and parsimonious than the underlying symptoms, but the theory provides little guidance on their 'optimal' construction. We experimented a bit with the definitions of $\mathrm{MH}$ and $\mathrm{PH}$. In particular, we estimated separate probit equations for each component of either $\mathrm{PH}$ and $\mathrm{MH}$, to notice that the effect of lifestyles and adverse working conditions on, say, the dummies for neck, knees, shoulder, hand and low back pain have the same sign and goes in the same direction, suggesting that the aggregation of the information into a single dummy is still informative. We obtained similar results by analyzing separately the single components of MH. Results are available upon request.

${ }^{4}$ Despite the growth of stress-related illness among European workers, MSDs remain one of the biggest causes of absence from work. It is estimated that up to $2 \%$ of European gross domestic product (GDP) is accounted for by the direct costs of MSDs each year (Bevan et al.2009).

${ }^{5}$ In the occupational health literature two theoretical models predict high health risks in workers exposed to adverse working conditions: the demand-control model (Karasek et al.1979 and Karasek and Theorell 1990) and the effort-reward imbalance model (Siegrist 1996). The first model predicts as the worst combination for one individual's health the joint interaction of high job demand and low job control. Psychological demands create stress, if the worker cannot control this stress because of a low level of control, the accumulation of this unreleased stress has a negative impact on the workers' health. Instead, the second model emphasizes the nonreciprocity of social exchange at the firm. The effort--reward imbalance model considers the categories of effort, such as the demands of the job and the motivation of workers in challenging situations, and reward at
} 
main dimensions of work-related risks are relevant for health: Demand, which is associated with demanding physical working conditions; Control, which refers to the degree of control on performed tasks and to the possibility to develop new skills and Reward, which reflects the prospects for career progression and of receiving the deserved support by colleagues (Bockermann and Illmakunnas, 2008; Cox, Griffiths and Rial-González 2000, Stock et al., 2005).

With respect to the Demand dimension we use several indicators that cover physical exposure (loud noise or vibrations from tool hand or vibrations from strike whole body, etc), thermal exposure (temperature fluctuations or coldness or draft) and chemical exposure (skin contact with solvents or solvent vapour or passive smoke) and we define a summary indicator that provides a subjective evaluation of harms related to hazardous physical working conditions experienced at the workplace. This indicator is a dummy variable that takes value 1 if a set of physical hazards is experienced by the worker, such that the lowest category corresponds to the perception by a worker that a feature of working conditions is very much an adverse factor at the workplace: we recode them as 1 when the worker is ever exposed (scale 1-5) to this particular harm during her working time, and 0 if he/she is never exposed. Namely: physical hazards takes value 1 if the worker was exposed to: (i) noise so loud that he/she has to raise his/her voice to talk with other people; or (ii) vibrations from hand tools; or (iii) vibrations from strike his/her whole body; or (iv) bad lighting, (v) temperature fluctuations; (vi) coldness (work outdoor or in cold rooms) or draft; (vii) skin contact with refrigerants or lubricants; (viii) solvent vapour; (xi) or passive smoke; 0 otherwise.

Next we use three variables describing psychosocial work conditions. The first variable refers to the degree of Control the worker possesses over its job, and asks if the work involves repetitive tasks in the last two months ('Repetitive': do you repeat the same task many times per hour?/learn new things?/work varied?/can take the initiative?). The second and third variables refer to the Reward dimension. The first measures whether the worker receives or not help from his/her colleagues/supervisor ('No social support'). The second accounts for the worker's perception about her job (in)security ('Job worries'). This

work in terms of salary, esteem, job stability and available career opportunities. It predicts that a negative impact on health occurs when there is an imbalance between these two dimensions. 
takes value 1 if the worker mentions to worry about at least one of the following situations: (i) Losing job?; (ii) Transferred against will?; (iii) Made redundant because of new technology?, (iv) Difficult to find a new job?. We refer to this variable as job worries. We therefore concentrate on a subset of indicators as compared to the most comprehensive set used by Borg and Christensen (2000). Our rationale is to follow the same conceptual framework as defined by demand-control and effort- reward models, and to keep a number of indicators that can be operationalized effectively in the empirical model.

Also for the definition of lifestyles $(L S)$, finding a reasonable compromise between comprehensiveness and empirical tractability is not obvious. The World Health Organisation generally adopts a broad definition; “... the term lifestyle is taken to mean a general way of living based on the interplay between living conditions in the wide sense and individual patterns of behaviour as determined by sociocultural factors and personal characteristics". We use a narrower definition of lifestyle which focuses, on health related behaviour and accords with the literature on the determinants of health (e.g. Contoyannis and Jones, 2004; Lynch et al., 1996, 1997; Marmot et al., 1997). Following this definition in our data we are able to construct three indicators of lifestlyles. ${ }^{6}$ Smoking is defined in terms of whether the individual is a current smokers or not. Drinking is measured by a binary variable which indicates heavy alcohol consumption in the week before the interview. The indicator for obesity is calculated on the basis of the body mass index. ${ }^{7}$ This may be considered as an intermediate health indicator, rather than a 'pure' lifestyle. Nonetheless, it may be also treated as a proxy for unhealthy behaviours such as a wrong diet and insufficient physical activity. For this reason, throughout we will treat this variable as a summary indicator of unhealthy lifestyles (as in Borg and Kristensen, 2000).

We use a relatively parsimonious set of control variables. As to individual characteristics, we control for gender, 5 age dummies, marital status, 4 dummies for the

\footnotetext{
${ }^{6}$ With respect to lifestyles we are able to improve over Borg and Christensen (2000) adding another dimension of lifestyles that is heavy drinking. Other lifestyle measures that are common in the literature (Belloc and Breslow, 1972; Kenkel, 1995) are excluded from our analyses due either to the lack of a reasonable proxy (as in the case of good sleep) in the dataset or because the definition of the variables changed over time (exercise and good diet).

${ }^{7}$ The definition of the drinking and obesity variables is different across gender. The variable "Drink" takes value 1 with more than 2 drinks a day for men, and with more than 1 drink in the case of women. About obesity we follow Contoyannis and Jones (2004) and construct and indicator that takes value 1 if the BMI is greater than 30 for men and greater than 28.6 for women.
} 
number of children in the household, and 10 educational levels. The set of job characteristics (other than adverse working conditions $W C$ ) are 5 dummies for firm's size, 8 sector dummies and 3 occupation dummies. We further control for the natural logarithm of hourly wage and for time dummies. A description of the sample is presented in Table A1 in the Appendix of the paper.

In Table 1 we show some descriptive statistics on the distribution of health, lifestyle and job quality measures. We observe that the self-assessed level of health is very good/good for almost $80 \%$ of the workers included in the sample. With reference to specific health dimensions, good physical health (in terms of absence of any symptom related to physical problems) is reported by $60 \%$ of the sample while good job-related mental health is reported by $40 \%$ of the sample.

Table 1. Lifestyles and working conditions by health status (in percentage points)

\begin{tabular}{cccc}
\hline & $S A H$ & $M H$ & $P H$ \\
\hline Lifestyles: & & & \\
Drinker & 0.79 & 0.4 & 0.63 \\
Smoker & 0.78 & 0.43 & 0.57 \\
Obese & 0.67 & 0.4 & 0.56
\end{tabular}

Working conditions:

$\begin{array}{llll}\text { Physical hazards } & 0.79 & 0.41 & 0.57\end{array}$

No support from

$\begin{array}{llll}\text { colleagues } & 0.79 & 0.36 & 0.63\end{array}$

$\begin{array}{llll}\text { Job worries } & 0.77 & 0.34 & 0.57\end{array}$

\begin{tabular}{cccc} 
Repetitive work & 0.55 & 0.55 & 0.53 \\
\hline Mean & 0.72 & 0.41 & 0.57 \\
\hline
\end{tabular}

Even though some results may appear counterintuitive, the numbers in Table 1 could be driven by spurious correlations, since many compositional effects can drive the observed association between lifestyle, working conditions and health.

\section{Empirical strategy}

Leaving implicit the subscript for the $i$-th individual, a simple empirical specification of health equations which accounts for the fact that we use binary indicators of health is the following: 


$$
H_{j}=I\left(\alpha_{j} W C+\delta_{j} L S+\beta_{j} X_{j}+\varepsilon_{j}>0\right)
$$

where $I(\#)$ is an indicator function for the argument being true, $H$ is an health dummy for one of the $j$ dimensions considered: $S A H, P H, M H$. We analyse these three dimensions separately. $X_{j}$ are explanatory variables such as gender, education, age groups, hourly wage and family characteristics (civil status, presence of children). $\varepsilon_{j}$ are unobservable individual attributes affecting health; $L S$ includes three dummy variables for obesity, drinking and smoking. $W C$ includes four dummies for physical hazards, repetitive work, feeling no support from colleagues and job worries. Each effect is specific to $j$-th health dimension considered. We also allow the set of $X$ 's to vary with $j$, as so do the unobservables.

The longitudinal nature of our data would in principle enables us to add a dynamic dimension to the model: for example including lagged values of lifestyles and working conditions in the health equations (Contoyannis and Jones, 2004) or adding lagged health as a predictor of current health to capture its persistence (see Datta Gupta and Kristensen, 2008). But in this case we would lose one of the two waves, which is particularly problematic given that our full sample only counts about 6,000 observations and that the estimation of our structural model is demanding in terms of data. As discussed in the Appendix when presenting the theoretical model, we accommodate for the time dimension by interpreting $H$ as an indicator of current and future health. In this way, we can interpret health as dependent also on past lifestyle decisions and working conditions.

In absence of selection and endogeneity issues, (1) could be consistently estimated, e. g., with simple univariate probits. However, the relationship between health vis a vis lifestyles and working conditions may be plagued by endogeneity or reverse causality problems. With respect to the former, unobservable individual tastes may simultaneously affect lifestyles or working conditions, as well as the propensity to report physical and mental health problems or low levels of self-assessed health. Economic theory suggests that factors such as risk aversion or the intertemporal discount rate may play a major role. It is however difficult to formulate precise predictions about the direction of the endogeneity bias, because these two factors may work in opposite directions and differently for different lifestyles or working conditions. Consider for example smoking and physical health. A 
higher intertemporal discount rate may increase both the probability of smoking and the weight of past health problems in current evaluations, which in turn reduces the likelihood of good $\mathrm{PH}$ (which is lack of associated symptoms in the last twelve months). In this case the correlation through unobservables would be negative. By converse, a risk averse individual may be less likely to undertake risky activities such as smoking, drinking or being subject to physical hazards and, at the same time, more likely to report low levels of health. Then, the correlation would be positive. However, for other key regressors the correlation may have the opposite sign, for example if more risk averse individuals are more worried for their job or have preferences for repetitive jobs. ${ }^{8}$ Reverse causality emerges when, on average, perceived good health influences the propensity of unhealthy behaviours or the probability of being subject to risky working conditions. Again, this may go in either directions, also depending on the variable considered: healthier individuals may trade-off their health stock with unhealthy behaviours such as smoking, drinking or weight excess, resulting in a positive errors' correlation. On the contrary, they may start drinking to substitute the pain of feeling poor mental health. Or they may feel less likely to experience adverse working conditions such as being fired or not being considered by colleagues. Summing up, the evaluation of errors' correlation patterns is a matter of empirical investigation.

In the Appendix, we sketch a behavioural model that extends Contoyannis and Jones (2004) to include working conditions, and, starting from a static utility maximisation problem in which $L S$ and $W C$ are choice variables, offers insights about the identification of $L S$ and $W C$ genuine effects.

The structural model contains both health equations in (1), and health-specific reduced forms for the vectors of three lifestyles (label $k$ ) and four working conditions (label h):

$$
\begin{aligned}
& L S_{k}=I\left(\gamma_{k} Z+u_{k}>0\right), \\
& k=\text { smoker, drinker, obese }
\end{aligned}
$$

\footnotetext{
${ }^{8}$ Endogeneity may also be effective on the employers' side, if 'good' firms with a pleasant environment are workers' high-health firm (with health levels higher than expected given observable characteristics) and, at the same time, are less risky in terms of physical and psychosocial working conditions.
} 
$W C_{h}=I\left(\theta_{h} Z+v_{h}>0\right)$,

$h=$ psy sicalhazards, no supportfrom colleagues, job worries, repetitive work

For each $j$-th health indicator, (1), (2) and (3) define a fully recursive model that contains eight simultaneous equations freely correlated through unobservables.

The $Z$ vector includes the exogenous covariates in $X$ plus exclusion restrictions. Details about the criteria followed in excluding variables from $X$ and including them in $Z$ are in the next sub-section, where we discuss the identification strategy.

We assume normality of the error terms and estimate the model by Maximum Simulated Likelihood (MSL) as a multivariate probit (MVP) (Cappellari and Jenkins, 2003). ${ }^{9}$ The structural equations for health (either $S A H, M H$ or $P H$ ) and the seven reduced forms for $L S$ and $W C$ are jointly distributed as an eight-variate normal. ${ }^{10}$ The correlated errors have a correlation matrix estimated together with the coefficients. ${ }^{11}$ The univariate probit models are nested within the MVP framework, when for each $j$-th health equation, $\operatorname{corr}\left(\varepsilon_{j}, u_{k}\right)$ and $\operatorname{corr}\left(\varepsilon_{j}, v_{h}\right)$ are zero for all $k$ and $h$. A simple likelihood test for any of these correlations being zero is a test for the endogeneity of the corresponding variable in the health equation considered.

\footnotetext{
${ }^{9}$ Also fixed effects estimators for panel data may be used. However, in our case very few individuals change health status, lifestyles and working conditions over time. This makes both identification and estimation problematic, and we verified that fixed effect estimates are very imprecise and not informative. Accordingly, we treat our sample as a pooled cross section, however clustering the standard errors at the individual level.

${ }^{10}$ In principle one would also allow $S A H, M H$ and $P H$ to be correlated through unobservables, and we experimented on that. Simple trivariate probit estimates with exogenous $L S$ and $W C$ suggest that, as one may expect especially the cross-correlation between health variables is always positive and statistically significant. In the multivariate setting, allowing for this additional correlation source complicates the estimation and makes it difficult to get convergence to a global maximum. For this reason, we estimate separately the three health equations in our empirical analysis.

${ }^{11}$ In general, the identification of pooled models with endogenous regressors is based on variables in $Z$ that do not appear in $X$. In our specific case there is however another option available: according to Wilde (2000), given the high non linearity of the recursive multivariate probit model, its parameters are identified through the functional form, with no need of exclusion restrictions. In our empirical analysis we experimented with both identification approaches: we tried to estimate the model, first, without exclusion restrictions. By following the strategy suggested by Wilde (2000) we were able to get estimates for $S A H$ and $M H$, but not for $P H$ since the likelihood did not converge to a global maximum. However, the results for $S A H$ and $M H$ obtained without exclusion restrictions (available upon request) are very similar to the ones presented in next section. As a robustness check, we also estimate a different specification of the model with exclusion restrictions, in which, based on joint significance tests, we impose a number of asymmetries in the set of variables excluded from the health equations and used to identify, on the one side, lifestyles, and, on the other side, the set of working conditions. Results are again available upon request and are very similar to the ones discussed in the main text.
} 
Our econometric model allows to investigate some alternative hypotheses about the effect of each $k$-th lifestyle or $h$-th working condition on any $j$-th health dimension. We will be able to distinguish between four different cases: (1) the correlation coefficient between the errors of the equation $k$ (or $h$ ) and $\mathrm{j}$ is not statistically different from zero and the corresponding coefficient in the $j$-th equation is statistically significant. In this case the variable is exogenous with respect to the health dimension considered and its effect is causal; (2) the correlation coefficient is statistically significant while the coefficient is not. In this case the variable is endogenous and the correlation between errors is driven by unobserved heterogeneity (the so-called third variable hypothesis); (3) both the correlation coefficient and the coefficient are significant. In this case although the $k$-th (or $h$-th) variable is endogenous with respect to $j$, it also has a causal impact. The estimates of the correlation coefficient and of the causal effect will also give an idea of the relative importance of the two alternative explanations, i.e. third variable hypothesis vs causal effects; (4) the correlation coefficient and the coefficient itself are both insignificant, and in this case our analysis will not support any of the above hypotheses (see Bratti and Miranda, 2010).

\subsection{Identification}

The MVP model is formally identified through functional form and exclusion restrictions are unnecessary (Wilde, 2000). However, it may suffer from 'tenuous' identification and it may be useful to improve it setting some exclusion restrictions. They must satisfy two requirements. First, they need to be relevant, shifting the net benefit of choosing specific values of $L S$ and $W C$. The theoretical model sketched in the Appendix suggests that these shifters account for changes in exogenous income, market and implicit prices of lifestyles and working conditions, the amount of labour time needed to consume one unit of $L S$ and the amount of leisure time needed to consume $L S$ in terms of forgone income. Second, the identifying variables need to be excludable from the health equations once we control for $L S$ and $W C$.

The guidance offered by the economic theory in this context is subject to the limitations imposed by available information and the lack of sources of truly exogenous 
variation in the data. ${ }^{12}$ On the one hand, all the covariates included in the analysis education, age, gender, family status, region of residence; and job characteristics such as the occupation, the size of the firm and the employment sector - may act as potential shifters of either the direct, indirect and opportunity costs of lifestyle and working conditions. On the other hand, it is difficult to justify the ex-ante exclusion of a subset of these variables (or other variables in the survey) from the health equations.

Given these limitations, the final set of covariates included in each health structural equation are selected using a general-to-specific strategy. We start from a general specification with lifestyles and working conditions plus all the other explanatory variables. We estimate this general specification by univariate probits, one for each health variable. The results are in columns (i) of Table A2. Then, we run Wald tests for the exclusion of various groups of variables in each health equation. Groups that were statistically significant at $10 \%$ or more were retained in the final specification of the corresponding health equation. ${ }^{13}$ Through this variable selection process, different covariates were selected for exclusion from the final specification of the three health equations and included in $Z$ vectors.

For $S A H$, the exclusion restrictions are sector, size and regional dummies. For $P H$, we also exclude occupation dummies. For $M H$, we exclude occupation, size and regional dummies, but we retain sector dummies, given that they cannot be excluded based on insignificance tests. Hence, joint insignificance tests leave us with asymmetric exclusion restrictions between health measures. In principle, there are no reason why this should not be the case, since different health dimensions may have different 'production inputs'.

In the reduced forms for lifestyles and working conditions, the set of regressors is the same $(Z)$, and includes all the exogenous covariates. However, the number of exclusion restrictions is different according to the health dummy considered. Hence, while $Z$ is

\footnotetext{
${ }^{12}$ Balia and Jones (2008) use family background variables as exclusion restrictions to identify lifestyle indicators. We also experimented with the approach followed by Contoyannis and Jones (2004), who use one period lags of the exogenous variables $X_{j}$ as exclusion restrictions for current lifestyle indicators. However, using this strategy only a single cross section is available for the estimates. Maybe because the resulting sample is small as compared to the number of parameters, we encountered several problems to achieve convergence to a global maximum in the likelihood maximization.

${ }^{13}$ To ease the presentation, these exclusion Wald tests for the whole battery of controls are not presented here but available from the authors. However, in the last row of Table 2 we report the test of joint insignificance of all the variables that we exclude from the final specification of each health equation. This test somehow provides an overall assessment about the joint excludability of variables used as a source of identification.
} 
always the same, we let identification to be health-specific.

Once in columns (ii) of Table A2 we exclude these variables and re-estimate the probit health equations, the coefficients' of retained variables are largely unaffected by that (compare columns (i) and (ii) results). This stability in the estimates to the exclusion of identification restrictions is supportive of our empirical strategy. ${ }^{14}$

According to Tables A3, A4 and A5, columns (ii) to (viii), exclusion restrictions also relevant determinants of the first stages' equations: overall, the region of residence, the occupation, the size and the employment sector are statistically significant determinants of lifestyles (being a smoker, an heavy drinker or obese) and of adverse working conditions (being subject to physical hazards, receiving no support from colleagues, doing repetitive stuff, being worried about the job).

Back to our economic framework, regional dummies might capture variability in both average exogenous income and the implicit and explicit prices of $L S$ and $W C$ : for example, the average price of alcoholic drinks or of cigarettes, or the costs of loose the job. Interestingly, job-related variables such as occupation, size and sector is able to account for variability not only in working conditions, but also in lifestyles. According to our theoretical framework, this may be the case if they are able to capture variability in the amount of labour time needed to consume units of $L S$. For example, companies in different sectors may promote different smoking or drinking policies; similarly, being overweight is more or less compatible with working in certain occupations or in some sectors. ${ }^{15}$

\footnotetext{
${ }^{14}$ Of course, an empirically driven identification strategy is a rather informal way to assess excludability conditions, which in principle cannot be tested. On economic grounds, these exclusion restrictions suggest that, once we control for WC, LS and other covariates, the health effect of say, working in firms of sectors is absorbed by the fact that, e.g. working in a certain sector means being subject on average to a certain combination of physical and psychosocial working conditions, which is what really matters for individuals' perceived health.

${ }^{15}$ As a consistency check, we also performed a RESET test, which suggests that the health equations are not misspecified either with or without these restrictions. The RESET test is a useful and generally accepted diagnostic tool in this context, but we must advise that, according to Wooldridge (2002), it cannot be used to test for the presence of omitted variables, but only for the miss-specification of the functional form. In a preliminary step, we also estimated the model under alternative identifying assumptions (e.g. by excluding also log of wage and the number of children, which are only weakly significant in columns (i) of Table A2). We find that results are not very sensitive to the choice of variables that may reasonably excluded from the health equation based on significance tests. This suggests that, as has been found in other papers on similar topics, identification issues may not play a crucial role in the analysis of health determinants.
} 


\section{Results}

\subsection{Self-Assessed Health}

Table 2 includes results from both an univariate probit for $S A H$ where lifestyles and working conditions are exogenous, and the full recursive system estimated by multivariate probit. Table 2 presents the Average Partial Effects (APE) for the variables of interest and the associated standard deviations, plus the statistical significance of the corresponding coefficients as estimated by probit or multivariate probit models. ${ }^{16}$ Next, Table 3 illustrates the matrices of errors' correlations of the full recursive multivariate probits, which are useful to evaluate the extent of endogeneity issues, as well as to gauge whether lifestyles and working conditions co-vary through unobservables.

As expected, bad lifestyles and adverse working conditions have always a negative association with self-assessed health. This is true for both the exogenous and endogenous models, but with some differences. Results for simple probit estimates indicate a negative and significant effect for smoking and obesity, higher for the latter (13\% reduction in the probability of reporting good health) compared to the former (5\%), while the negative effect of drinking is not statistically significant. All the working conditions negatively affect the probability of reporting good health, with the higher importance attached to having job worries and being subject to physical hazards, with an APE of about $6 \%$.

Using the 1990 and 1995 waves of Danish data also used by us, Borg and Kristensen (2000) estimate a logit model and detect a positive statistical association between a worsening in $S A H$ between 1990 and 1995, and smoking and obesity.

Also adverse working conditions of the kind we consider appeared positively correlated with a decrease in perceived health. Using a random effect ordered probit, Datta Gupta and Kristensen (2008) similarly find a positive effect of satisfaction for the work environment on $S A H$.

Once unobservable heterogeneity is accounted, the overall picture is similar but the negative effects that are statistically significant are even larger than before. In particular,

\footnotetext{
${ }^{16}$ The model is estimated by MSL using the command mvprob in Stata. The coefficients of the health equation estimated by the multivariate probit then are used to compute predicted health probabilities from the univariate standard normal. To get the marginal (i.e. partial) effects we averaged predicted probabilities over individual characteristics. The level of significance of the partial effects in Tables 2,4 and 6 is that of the corresponding estimated coefficients. They are reported in Table A2, columns (ii) for the univariate probit; and in Tables A3, A4 and A5 in the appendix for the multivariate probit models.
} 
drinking a lot reduces self-assessed health by about $20 \%$, and being obese of about $17 \%$. These effects are substantial, implying non negligible costs of unhealthy behaviours in terms of perceived overall health. By converse, smoking is no longer statistically significant. The errors' correlation pattern of Table 3 adds useful insights. The correlation between heavy drinking and $S A H$ is positive (0.36), which is consistent with both a risk aversion which may act as a 'third variable' or a reverse causality interpretation where individuals trade-off good health with unhealthy behaviours.

Table 2. Self-assessed health $(S A H)$ estimates (Average partial effects)

\begin{tabular}{|c|c|c|c|c|c|c|}
\hline & \multicolumn{3}{|c|}{ Probit } & \multicolumn{3}{|c|}{ Multivariate probit } \\
\hline & $A P E$ & St.Dv. & $\begin{array}{l}\text { Stat. Sign. } \\
\text { coeff }\end{array}$ & $A P E$ & St.Dv. ${ }^{S}$ & $\begin{array}{l}\text { Stat. Sign. } \\
\text { coeff }\end{array}$ \\
\hline \multicolumn{7}{|l|}{ Lifestyles: } \\
\hline Smoker & -0.049 & 0.017 & $* * *$ & -0.035 & 0.016 & \\
\hline Drinker & -0.008 & 0.003 & & -0.196 & 0.063 & $* *$ \\
\hline Obese & -0.127 & 0.035 & $* * *$ & -0.167 & 0.057 & $* *$ \\
\hline \multicolumn{7}{|l|}{ Working conditions: } \\
\hline Physical hazards & -0.057 & 0.019 & $* * *$ & -0.088 & 0.040 & $* *$ \\
\hline No support from colleagues & -0.031 & 0.011 & $* * *$ & -0.170 & 0.060 & $* * *$ \\
\hline Job worries & -0.065 & 0.020 & $* * *$ & -0.127 & 0.050 & $* * *$ \\
\hline Repetitive work & -0.026 & 0.009 & $* * *$ & -0.0192 & 0.009 & \\
\hline N. obs. & \multicolumn{3}{|c|}{6,071} & \multicolumn{3}{|c|}{6,071} \\
\hline Log likelihood & \multicolumn{3}{|c|}{$-2,521.61$} & \multicolumn{3}{|c|}{$-25,278.69$} \\
\hline
\end{tabular}

Notes: The multivariate probit estimates are obtained by Maximum Simulated Likelihood with the mvprobit command in Stata with 75 random draws. Full results in terms of estimated coefficients are in Table A2 for the probit model with exclusion restrictions (specifications (iii)) and in Table A3 for the multivariate probit. The APE (Average Partial Effects) are calculated for each observation using the marginal (i.e. univariate) distribution of the health outcome, and then averaging over individuals. In the probit case, this is different from using the post-estimation command in Stata dprobit, which evaluate the marginal effect at the mean of observable characteristics. Sample standard deviations, that measure variation of the partial effects across individuals are reported along with the corresponding APE. We also report here the statistical significance of the associated coefficient, as taken from Tables A2 and A3. The exclusion restrictions in the probit are the sector, size and regional dummies. Statistical significance of coefficients: $*=10 \%$ level; $* *=5 \%$ level; $* * *=1 \%$ level.

For smoking, the correlation coefficient is negative and statistically significant, perhaps induced by the intertemporal discount rate. This is in line with the findings of most of the literature (Bratti and Miranda, 2010).

For what concerns working conditions, passing from probit estimates to MVP the associated estimated coefficients are still significant except the dummy for repetitive work, 
and in general APE is higher. This is consistent with the errors' correlation structure of Table 3. The correlation is positive, and statistically significant in the case of not receiving support from colleagues and job worries. This implies that the univariate probit underestimates (in absolute value) the true $S A H$ effect of such working conditions. According to previous section's discussion, positive selection may be the result of 'positive' reverse causality: healthier individuals are more able to manage the lack of support or job insecurity. Instead, physical hazards seem to be exogenous to $S A H$, while for repetitive work we are in case 4) (according to the previous section taxonomy), where both the coefficient and the correlation are insignificant.

Our results for $S A H$ are qualitatively similar to those by Contoyannis and Jones (2004), who find a complex correlation structure between errors of $S A H$ and $L S$ equations and that obesity and physical activity are the only variables who are significant $S A H$ determinants when endogeneity is accounted for. Across groups, there are some interesting differences between physical and psychosocial working conditions: for example the former are correlated with all of our lifestyle indicators, the latter especially with smoking.

The importance of controlling simultaneously for both lifestyles and working conditions is also revealed by Table 3, which shows that there exists substantial correlation between the reduced forms errors: in this is true especially within the groups of both physical and psychosocial working condition variables. We also find that the two working conditions spheres - physical and psychosocial - are correlated each other.

A long standing psychological and epidemiological literature has advanced several explanations for why working conditions and behavioural risk factors might be empirically correlated with health through unobservables. In general, the idea is that individuals may respond to environmental challenges by modifying their behaviour (Bhui, 2002). ${ }^{17}$ As smoking is assumed to ease stress, smokers may smoke most when exposed to strenuous work in order to calm themselves down (Perkins and Grobe 1992, Parrott 1999).

\footnotetext{
17 Accordingly, employees might show a tendency to compensate strenuous work such as either heavy physical or psychosocial demands with unhealthy behaviors. For example, these studies suggest that physically and psychosocially strenuous working conditions and other work-related factors extend their effects outside the workplace and influence the behaviors potentially via coping strategies related to drinking or smoking (Greenberg and Grunberg 1995).
} 
Table 3. Correlation coefficients from the multivariate probit for self-assessed health $(S A H)$

\begin{tabular}{|c|c|c|c|c|c|c|c|c|}
\hline & $S A H$ & Smoker & Drinker & Obese & Phys. hazards & $\begin{array}{c}\text { No support from } \\
\text { colleagues }\end{array}$ & Job worries & $\begin{array}{l}\text { Repetitive. } \\
\text { work }\end{array}$ \\
\hline$\overline{S A H}$ & 1 & & & & & & & \\
\hline Smoker & $-0.10^{*}$ & 1 & & & & & & \\
\hline Drinker & $0.357 * *$ & $-0.224 * * *$ & 1 & & & & & \\
\hline Obese & 0.102 & $-0.093 * * *$ & -0.026 & 1 & & & & \\
\hline Physical hazards & 0.127 & $0.041 *$ & $0.073 * *$ & $0.118 * * *$ & 1 & & & \\
\hline No sup. from colleag & $0.344 * * *$ & $-0.062 * *$ & -0.011 & -0.021 & $0.051 * * *$ & 1 & & \\
\hline Job worries & $0.181 *$ & 0.025 & 0.038 & 0.014 & $0.137 * * *$ & $0.079 * * *$ & 1 & \\
\hline Repetitive work & 0.009 & $0.070 * *$ & 0.006 & 0.009 & $0.188 * * *$ & 0.021 & $0.083 * * *$ & 1 \\
\hline $\begin{array}{l}\text { LR-test: All correl. coeffs. } \\
\text { set to zero (no endogeneity) }\end{array}$ & & & & $\operatorname{Chi} 2(28)=28$ & $45 ; \mathrm{p}$-value $=0$ & 0000 & & \\
\hline
\end{tabular}


Table 4. Physical health $(P H)$ estimates (Average partial effects)

\begin{tabular}{|c|c|c|c|c|c|c|}
\hline \multirow[b]{3}{*}{ Lifestyles: } & \multicolumn{3}{|c|}{ Probit } & \multicolumn{3}{|c|}{ Multivariate probit } \\
\hline & \multirow[t]{2}{*}{$A P E$} & St.Dv. & \multirow[t]{2}{*}{$\begin{array}{c}\text { Stat. Sign. } \\
\text { coeff }\end{array}$} & \multirow[t]{2}{*}{$A P E$} & \multicolumn{2}{|c|}{ St.Dv. $\begin{array}{c}\text { Stat. Sign. } \\
\text { coeff }\end{array}$} \\
\hline & & & & & & \\
\hline Smoker & -0.075 & 0.007 & $* * *$ & 0.033 & 0.006 & \\
\hline Drinker & 0.019 & 0.002 & & -0.004 & 0.001 & \\
\hline Obese & -0.038 & 0.004 & $* *$ & -0.051 & 0.008 & \\
\hline \multicolumn{7}{|l|}{ Working conditions: } \\
\hline Physical hazards & -0.117 & 0.011 & $* * *$ & -0.128 & 0.020 & $* *$ \\
\hline No support from colleagues & -0.0021 & 0.0002 & & -0.213 & 0.027 & $* * *$ \\
\hline Job worries & -0.054 & 0.006 & $* * *$ & -0.146 & 0.021 & $* *$ \\
\hline Repetitive work & -0.046 & 0.005 & $* * *$ & -0.104 & 0.017 & \\
\hline N. obs. & \multicolumn{3}{|c|}{6,071} & \multicolumn{3}{|c|}{6,071} \\
\hline Log likelihood & \multicolumn{3}{|c|}{$-3,820.69$} & \multicolumn{3}{|c|}{$-26,585.18$} \\
\hline \multicolumn{7}{|c|}{$\begin{array}{l}\text { Notes: The multivariate probit estimates are obtained by Maximum Simulated Likelihood with the mvprobit } \\
\text { command in Stata with } 75 \text { random draws. Full results in terms of estimated coefficients are reported in Table } \\
\text { A2 for the probit model with exclusion restrictions (specifications (iii)) and in Table A4 for the multivariate } \\
\text { probit. The APE (Average Partial Effects) are calculated for each observation using the marginal (i.e. } \\
\text { univariate) distribution of the health outcome, and then averaging over individuals. In the probit case, this is } \\
\text { different from using the post-estimation command in Stata dprobit, which evaluate the marginal effect at the } \\
\text { mean of observable characteristics. Sample standard deviations, that measure variation of the partial effects } \\
\text { across individuals are reported along with the corresponding APE. We also report here the statistical } \\
\text { significance of the associated coefficient, as taken from Tables A2 and A4. The exclusion restrictions in the } \\
\text { probit are occupation, sector, size and regional dummies. Statistical significance of coefficients: } *=10 \% \\
\text { level; } * *=5 \% \text { level; } * * *=1 \% \text { level. }\end{array}$} \\
\hline
\end{tabular}

\subsection{Physical and Mental Health}

We now investigate whether the effect of $L S$ and $W C$ is heterogeneous across specific health dimensions. Tables 4 and 6 are the analogues of Table 2 but for a model where $P H$ and $M H$ are determined together with reduced forms for $L S$ and $W C$. Tables 5 and 7 report the corresponding matrix of estimated correlation across errors.

We start from $P H$ and look at the effect of lifestyles first. As expected, in simple probit the APE for smoking is negative (- 7.5\%) and statistically significant and so is obesity, with an APE of about 4\%. However, once we move to MVP all these effects are statistically insignificant. The inspection of Table 5 reveals that the correlation coefficients have the same sign as in the $S A H$ model (all positive except for smoking) but are no longer 
significant. This is case (4) of our previous classification, and our analysis is not able to provide any useful prediction about the structural effect of our lifestyles on our indicator of musculoskeletal health.

As far as working conditions simple probit estimates suggest they always play a negative and statistically significant role with the exception of the dummy for not perceiving support from colleagues. As we might expect, being subject to physical hazard is negatively associated with (the APE is 11.7\%). Job instability is associated with 5\% reduction in physical health, which is similar to the APE for repetitive tasks.

Except in the case of physical hazards that are consistently estimated also by probit, MVP shows larger effects for not being supported by colleagues and of job worries, by 21 and 15 percent, respectively. In this case, the pattern is similar to what we observed for $S A H$. Also correlation coefficients are shown positive and statistically significant (positive selection). On the policy side, we show that adverse psychosocial 'soft' working conditions are able to significantly affect an 'hard' dimensions of health, which it is not obvious a priori.

Tables 6 and 7 presents the results for the $M H$ model. Starting from lifestyles, in simple probits the determinants that play a major role are being obese and being an heavy drinker. However, as found in several studies the latter is not structural, since it disappears in the MVP. The fact that in Table 7 the associated correlation coefficient is insignificant does not allow to get any clear insight about the relationship between drinking and mental health. 
Table 5. Correlation coefficients from the multivariate probit for physical health $(P H)$

\begin{tabular}{|c|c|c|c|c|c|c|c|c|}
\hline & $P H$ & Smoker & Drinker & Obese & Phys. hazards & $\begin{array}{c}\text { No support from } \\
\text { colleagues }\end{array}$ & Job worries & $\begin{array}{c}\text { Repetitive } \\
\text { work }\end{array}$ \\
\hline$P H$ & 1 & & & & & & & \\
\hline Smoker & -0.180 & 1 & & & & & & \\
\hline Drinker & 0.012 & $0.225 * * *$ & 1 & & & & & \\
\hline Obese & 0.047 & $-0.094 * * *$ & -0.020 & 1 & & & & \\
\hline Physical hazards & 0.079 & $0.041^{*}$ & $0.074 * * *$ & $0.117 * * *$ & 1 & & & \\
\hline No support from colleagues & $0.386 * * *$ & $-0.064 * *$ & -0.017 & 0.018 & $0.051 * *$ & 1 & & \\
\hline Job worries & $0.194 *$ & 0.024 & 0.037 & 0.018 & $0.137 * * *$ & $0.083 * * *$ & 1 & \\
\hline Repetitive work & 0.127 & $0.067 * *$ & 0.004 & 0.007 & $0.189 * * *$ & 0.024 & $0.084 * * *$ & 1 \\
\hline
\end{tabular}

Notes: Statistical significance of coefficients: $*=10 \%$ level; $* *=5 \%$ level; $* * *=1 \%$ level. 
Similarly to Table 3 , the correlation coefficient for smoking is negative and that for obesity positive, both significant. This is reflected in the MVP estimates: being obese increases the probability to suffer from mental health problems by 15 percent; interestingly, smoking increases the likelihood of not suffering from mental illness by 16 percent. Other papers found that smoking has a positive effect on some components of mental health (e. g. Parrott, 1999; Warburton, 1992) suggesting that smoking aids mood control and acts through reducing smokers feelings of anxiety and anger. Of course, a well-known literature in medicine shows that smoking has severe negative consequences for many health dimensions, which in a policy perspective compensate by far and large the positive effect we detect for our mental health measure.

Moving to WC variables, except for repetitive work that is never precisely estimated, they all have a substantial, negative and statistically significant MVP effect on $M H$. For psychosocial hazards - job worries (APE -12 percent) and not receiving support from colleagues (-19.5 percent), this is not surprising. The interesting result is that also being subject to physical hazard creates a clear thread to mental health (APE is -21 percent). The inspection of the correlation matrix in Table 7 also reveals a positive association between the physical health and $M H$ unobservables (maybe induced to a 'third variable' such as risk aversion), which creates a downward bias in simple probit estimates. 
Table 6. Mental health $(M H)$ estimates (Average Partial Effects)

\begin{tabular}{|c|c|c|c|c|c|c|}
\hline & \multicolumn{3}{|c|}{ Probit } & \multicolumn{3}{|c|}{ Multivariate probit } \\
\hline & $A P E$ & St.Dv. & $\begin{array}{c}\text { Stat. Sign. } \\
\text { coeff }\end{array}$ & $A P E$ & St.Dv. ${ }^{S}$ & $\begin{array}{l}\text { tat. Sign. } \\
\text { coeff }\end{array}$ \\
\hline & \multicolumn{6}{|c|}{ Lifestyles: } \\
\hline Smoker & -0.014 & 0.002 & & 0.162 & 0.028 & $* *$ \\
\hline Drinker & -0.060 & 0.008 & $* * *$ & -0.051 & 0.011 & \\
\hline Obese & -0.043 & 0.005 & $* *$ & -0.154 & 0.036 & $*$ \\
\hline \multicolumn{7}{|l|}{ Working conditions: } \\
\hline Physical hazards & -0.063 & 0.007 & $* * *$ & -0.210 & 0.036 & $* * *$ \\
\hline No support from colleagues & -0.071 & 0.008 & $* * *$ & -0.195 & 0.035 & $* * *$ \\
\hline Job worries & -0.147 & 0.017 & $* * *$ & -0.118 & 0.024 & $*$ \\
\hline Repetitive work & -0.029 & 0.003 & $* *$ & 0.092 & 0.019 & \\
\hline N. obs. & & 6,071 & & & 5,071 & \\
\hline Log likelihood & & $-3,837.90$ & & & 593.266 & \\
\hline
\end{tabular}

Notes: The multivariate probit estimates are obtained by Maximum Simulated Likelihood with the mvprobit command in Stata with 75 random draws. Full results in terms of estimated coefficients are reported in Table A2 for the probit model with exclusion restrictions (specifications (iii)) and in Table A5 for the multivariate probit. The APE (Average Partial Effects) are calculated for each observation using the marginal (i.e. univariate) distribution of the health outcome, and then averaging over individuals. In the probit case, this is different from using the post-estimation command in Stata dprobit, which evaluate the marginal effect at the mean of observable characteristics. Sample standard deviations, that measure variation of the partial effects across individuals are reported along with the corresponding APE. We also report here the statistical significance of the associated coefficient, as taken from Tables A2 and A5. The exclusion restrictions in the probit are occupation, size and regional dummies. Statistical significance of coefficients: $*=10 \%$ level; $* *=$ $5 \%$ level; $* * *=1 \%$ level. 
Table 7. Correlation coefficients from the multivariate probit for mental health $(M H)$

\begin{tabular}{|c|c|c|c|c|c|c|c|c|}
\hline & $M H$ & Smoker & Drinker & Obese & Phys. hazards & $\begin{array}{c}\text { No support from } \\
\text { colleagues }\end{array}$ & Job worries & $\begin{array}{c}\text { Repetitive. } \\
\text { work }\end{array}$ \\
\hline$\overline{M H}$ & 1 & & & & & & & \\
\hline Smoker & $-0.327 * * *$ & 1 & & & & & & \\
\hline Drinker & -0.037 & $0.224 * * *$ & 1 & & & & & \\
\hline Obese & $0.234 *$ & $-0.097 * * *$ & -0.023 & 1 & & & & \\
\hline Physical hazards & $0.262 * *$ & $0.039 *$ & $0.074 * *$ & $0.121 * * *$ & 1 & & & \\
\hline No support from colleagues & $0.264 * *$ & $-0.064 * *$ & -0.016 & 0.022 & $0.053 * *$ & 1 & & \\
\hline Job worries & 0.118 & 0.024 & 0.037 & 0.015 & $0.137 * * *$ & $0.080 * * *$ & 1 & \\
\hline Repetitive work & $-0.193 *$ & $0.068 * * *$ & 0.005 & 0.003 & $0.187 * * *$ & 0.021 & $0.085 * * *$ & 1 \\
\hline $\begin{array}{l}\text { LR-test: All correl. coeffs. } \\
\text { set to zero (no endogeneity) }\end{array}$ & & & & $(28)=28 ?$ & $6 ; p$-value $=0.0$ & 000 & & \\
\hline
\end{tabular}

Notes: Statistical significance of coefficients: $*=10 \%$ level; $* *=5 \%$ level; $* * *=1 \%$ level. 


\section{Conclusions}

In this paper we investigate whether workers' health is affected by adverse working conditions (physical hazards, repetitive work, job worries and not being supported by colleagues) and by risky lifestyles (smoking, drinking and being obese).

We use Danish data for 2000 and 2005 that provide detailed information on lifestyles, working conditions and health matched with individual and establishments administrative records. Our data allow us to define three outcomes: self-assessed health, and mental and physical health. Our main set of result is by a multivarite probit approach because of the potential endogeneity of lifestyles and working conditions. We find that standard probits tend in general to underestimate (in absolute values) true effects.

With respect to lifestyles, their effect is negative and statistically significant especially for self-assessed health. For physical health, measured by absence of musculoskeletal problems, we are not able to detect any causal relationship. For mental health, we find a positive effect of smoking and negative of obesity. Taken at its face value, the first one challenges the common wisdom that good lifestyles practices are important to promote higher levels of mental well-being, although our mental health indicator refers to specific symptoms (e.g. stress at work) mediated by individual perceptions.

Physical adverse working conditions matter for both mental and physical health: their effects on mental health of individuals is as much important as that on musculoskeletal diseases. Similarly, psychosocial working conditions - and especially the support received from colleagues and presence of job worries - are indeed important determinants of both mental and physical health. This should be taken into account when considering their consequences on workers' well-being.

On the policy side, our results are informative for the design of interventions to promote specific health domains by reducing people's engagement in health-damaging behaviour and by improving their working conditions.

In a country like Denmark, which is traditionally at the frontier for safety at the workplace, this may also challenge the perceived effectiveness of policies that in the middle of the last decade promoted good practices to reduce job hazards and improve health levels. 
Appendix

\section{Theoretical framework}

A simple economic model may be useful to summarise the main implications for the empirical analysis of Sections 4 and 5. Our approach is similar to Contoyannis and Jones (2004), whose theoretical model for lifestyle and health choices can be modified to address our case, where health is also a function of working conditions. For simplicity, we consider health as a consumption good which directly affects current utility. The set up can be easily extended to the infinite horizon case, where health is also an investment good as in Grossman (1972), see Balia and Jones (2008). The implications for the empirical analysis are similar.

The individual's utility may be expressed as follows:

$$
U\left(W C, L S, H ; X_{U}, \varepsilon_{u}\right)
$$

$U$ is overall utility or satisfaction, which comprises non-work utility (leisure, family time) and work-related utility. The latter depends on a number of job attributes and working conditions $W C$, which may enter directly the utility function as they are typically not adequately compensated (e.g.: bad working conditions are not fully compensated by higher wages as in Rosen, 1974). At least to some extent, jobs are chosen by individuals, and, therefore, so are their characteristics. Utility is also function of a bundle of costly activities under the label "lifestyle" $L S$ and of health $H . X_{U}$ and $\varepsilon_{u}$ are vectors of individual observable and unobservable (respectively) characteristics affecting preferences.

We also assume that health $(H)$ is produced with the following technology:

$$
H=H\left(L S, W C ; X_{H}, \varepsilon_{H}\right)
$$

where $X_{U}$ and $\varepsilon_{u}$ are exogenous observable and unobservable individual characteristics affecting health. $H$ can be thought either as a scalar (such as the overall general health of the individual), or as a vector of different and health components: for example, physical and mental health; health at work and health at home and so on. The health production function can be substituted into the utility function to get:

$$
U(W C, L S, H ; X, \varepsilon)
$$

where $X$ is the union of the partly overlapping vectors $X_{U}$ and $X_{H}$, and similarly for $\varepsilon$. 
To get the solution to the utility maximisation problem relative to $L S, W C$ and $H$, we need to combine the above equations with money and time constraints, which, in its compact formulation, can be expressed as follows:

$$
\left(p_{L S}+w \tau_{L S}+\pi_{L S}\right)^{\prime} L S+\left(p_{W C}+\pi_{W C}\right)^{\prime} W C \leq T I=m+w T
$$

where $m$ is exogenous income, $w T$ is total labour income if the individual uses all the time endowment $T$ to work at the exogenous wage rate $w . p_{L S}$ and $p_{W C}$ are vectors of market and implicit prices of the goods included among 'lifestyles' and 'working conditions'. $w \tau_{L S}$ is product between the opportunity cost of lifestyles practices during leisure time (in terms of forgone income) and the amount of leisure time needed to consume one unit of $L S . \pi_{L S}$ and $\pi_{W C}$ are the amount of labour time needed to consume one unit of $L S$ and $W C$, respectively. Here is implicit the assumption that lifestyles are consumed both at work and at home, while working conditions can be consumed only at work. The opportunity cost of lifestyles in non-working time (such as smoking when watching the TV) is forgone labour income, while there is no direct money equivalent for the same activity performed during working time. Hence, $\left(p_{L S}+w \tau_{L S}+\pi_{L S}\right)^{\prime} L S$ and $\left(p_{W C}+\pi_{W C}\right)^{\prime} W C$ are linear combinations expressing the total money equivalent of the overall cost of lifestyles activities and job characteristics.

By combining the above expressions for utility and time plus money constraint, the solution of the model is rather straightforward. In this way, the shadow price of each good, and therefore, the demand for each lifestyle and working condition, is dependent on the wage rate, which varies across individuals. In particular, the solution to the model allows to define a set of demand functions for optimal levels of $L S, W C$ and $H::^{18}$

$$
\begin{aligned}
& L S^{*}=L S(Z, \varepsilon) \\
& W C^{*}=W C(Z, \varepsilon) \\
& H^{*}=H(Z, \varepsilon)
\end{aligned}
$$

where $Z$ combines $X$ (the set of exogenous individual characteristics of the model $X_{U}$ and $X_{H}$ ) and all the parameters used in the maximisation problem (in particular, the wage

\footnotetext{
${ }^{18}$ See Contoyannis and Jones (2004) for details about the formal derivation of demand equations in a similar setting.
} 
rate $w$, prices and time shares). $\varepsilon$ is the union of $\varepsilon_{u}$ and $\varepsilon_{H}$. These demand functions are reduced forms and do not allow to evaluate separately preference and technological parameters, that is the impact of lifestyles and working conditions on health indicators, which is the core of our analysis. The empirical models combines (A1), (A2) and (A3), where the former is the structural equation for health and the other two are reduced forms for lifestyle and health. Finally, a couple of further considerations. First, in the above discussion we do not consider the effect of the time dimension on actual choices. However, for example in the production of health, the time dimension is indeed important but can be easily accommodated in a simple way by interpreting $H$ as an indicator of current and future health. In this way, we can think at health as dependent also on past lifestyle decisions and working conditions (compare with Balia and Jones, 2008, who specify a dynamic model for the evolution of health). In principle, this may affect the specification of the empirical model (contemporaneous versus lagged effects). We discussed more on that when describing our estimation methodology (in Section 4). Second, the mapping between the theoretical and the empirical model is of course not perfect. On the one hand, while we have focused on interior solutions, the data reveals the prevalence of corner solutions for lifestyles and working conditions. On the other hand, while we have assumed continuous variables for $H, L S$ and $W C$, - so that utility can be maximised by differentiation to get continuous demand functions - the data often provide instead binary or discrete indicators, such as ordered measures of self-assessed health or dummies for the presence/absence of a given characteristics (e.g. drinking or not). 
Table A1. Summary statistics

\begin{tabular}{|c|c|c|c|}
\hline Variable & Description & Mean & S.d. \\
\hline$S A H$ & Self-assessed health & 0.78 & \\
\hline$M H$ & mental health & 0.43 & \\
\hline PH & physical health & 0.64 & \\
\hline Female & 1 if female & 0.36 & \\
\hline Ageless25 & 1 if worker is less than 24 years of age & 0.125 & \\
\hline Age2534 & 1 if worker is between 25 and 34 years of age & 0.233 & \\
\hline Age 3544 & 1 if worker is between 35 and 44 years of age & 0.287 & \\
\hline Age4554 & 1 if worker is between 45 and 54 years of age & 0.223 & \\
\hline Age54plus & 1 if worker is more than 54 years of age & 0.129 & \\
\hline Educ1 & 1 if 7-klasse & 0.05 & \\
\hline Educ2 & 1 if 8-klasse & 0.016 & \\
\hline Educ3 & 1 if 9-klasse & 0.058 & \\
\hline Educ4 & 1 if 10-klasse & 0.113 & \\
\hline Educ5 & 1 if gymnasium & 0.101 & \\
\hline Educ6 & 1 if higher commercial exam & 0.441 & \\
\hline Educ7 & 1 if higher technical exam & 0.032 & \\
\hline Educ8 & 1 if vocational education & 0.046 & \\
\hline Educ9 & 1 if boarding school & 0.073 & \\
\hline Educ10 & 1 if $\mathrm{BA}$ or more & 0.067 & \\
\hline Married & 1 if married & 0.61 & \\
\hline Widow & 1 if a widow & 0.01 & \\
\hline Divorced & 1 if divorced & 0.08 & \\
\hline Child1 & 1 if has no children & 0.54 & \\
\hline Child2 & 1 if has one child & 0.17 & \\
\hline Child3 & 1 if has two children & 0.21 & \\
\hline Child4 & 1 if has three or more children & 0.06 & \\
\hline Sect1 & 1 for manufacturing & 0.28 & \\
\hline Sect 2 & 1 for construction and electricity & 0.05 & \\
\hline Sect 3 & 1 for wholesale & 0.22 & \\
\hline Sect 4 & 1 for hotels and restaurant & 0.034 & \\
\hline Sect5 & 1 for transport & 0.09 & \\
\hline Sect6 & 1 for financial sector & 0.088 & \\
\hline Sect7 & 1 for PA & 0.056 & \\
\hline Sect8 & 1 for Education & 0.11 & \\
\hline Size1 & 1 for firm size between 1 and 5 & 0.197 & \\
\hline Size2 & 1 for firm size between 6 and 50 & 0.314 & \\
\hline Size 3 & 1 for firm size between 50 and 200 & 0.129 & \\
\hline Size4 & 1 for firm size between 200 and 500 & 0.234 & \\
\hline Size5 & 1 for firm size is more than 500 & 0.126 & \\
\hline Logwage & natural logarithm of real monthly wages & 5.21 & 0.34 \\
\hline Manager & 1 if manager & 0.03 & \\
\hline White & 1 if white collar & 0.28 & \\
\hline
\end{tabular}




\begin{tabular}{llc} 
Blue & 1 if blue collar & 0.69 \\
Obesity & 1 if obese & 0.15 \\
Drink & 1 if heavy drinker & 0.18 \\
Smoke & 1 if currently smoker & 0.31 \\
Physical hazards & 1 if harmful physical conditions at work & 0.39 \\
No support from colleagues & 1 if no support from colleagues & 0.41 \\
Repetitive work & 1 if work is repetitive & 0.57 \\
Job worries & 1 if worries about job stability & 0.35 \\
Reg1 & 1 if region is Northern area & 0.29 \\
Reg2 & 1 if region is Copenhagen area & 0.4 \\
Reg3 & 1 if region is Southern area & 0.31 \\
Y05 & 1 if year is 2005 & 0.61 \\
\hline
\end{tabular}


Table A2. Probit estimates coefficients (excluded, included lifestyles and working conditions)

\begin{tabular}{|c|c|c|c|c|c|c|c|c|c|c|c|c|}
\hline \multirow[t]{3}{*}{ Dep. Var $(s)$} & \multicolumn{2}{|c|}{$\underline{S A H}$} & \multicolumn{4}{|c|}{$\underline{P H}$} & \multicolumn{6}{|c|}{$\underline{M H}$} \\
\hline & \multicolumn{2}{|c|}{$(i)$} & \multicolumn{2}{|c|}{ (ii) } & \multicolumn{2}{|c|}{$\overline{(i)}$} & \multicolumn{2}{|l|}{ (ii) } & \multicolumn{2}{|c|}{$\overline{(i)}$} & \multicolumn{2}{|l|}{ (ii) } \\
\hline & Coef. & $z$ & Coef. & $z$ & Coef. & $z$ & Coef. & $z$ & Coef. & $z$ & Coef. & $z$ \\
\hline Smoker & -0.213 & -4.77 & -0.210 & -4.71 & -0.208 & -5.48 & -0.206 & -5.45 & -0.042 & -1.11 & -0.037 & -0.97 \\
\hline Drinker & -0.033 & -0.54 & -0.034 & -0.57 & 0.059 & 1.11 & 0.053 & 1 & -0.177 & -3.31 & -0.173 & -3.25 \\
\hline Obese & -0.476 & -8.21 & -0.479 & -8.3 & -0.105 & -1.98 & -0.105 & -1.99 & -0.124 & -2.28 & -0.122 & -2.25 \\
\hline Phys. hazards & -0.259 & -5.77 & -0.253 & -5.7 & -0.328 & -8.83 & -0.327 & -9 & -0.186 & -5.12 & -0.181 & -5.01 \\
\hline $\begin{array}{l}\text { No supp. from } \\
\text { colleagues }\end{array}$ & -0.132 & -3.20 & -0.134 & -3.24 & 0.001 & 0.02 & -0.006 & -0.18 & -0.197 & -5.53 & -0.196 & -5.53 \\
\hline Job worries & -0.276 & -6.57 & -0.277 & -6.63 & -0.151 & -4.23 & -0.149 & -4.2 & -0.403 & -11.02 & -0.404 & -11.09 \\
\hline Repetit. work & -0.111 & -2.45 & -0.117 & -2.58 & -0.124 & -3.32 & -0.128 & -3.45 & -0.091 & -2.42 & -0.083 & -2.24 \\
\hline Female & 0.097 & 2.06 & 0.110 & 2.4 & -0.230 & -5.82 & -0.222 & -5.87 & -0.224 & -5.64 & -0.229 & -5.86 \\
\hline Ageless 25 & 0.081 & 0.83 & 0.086 & 0.89 & -0.171 & -2.20 & -0.180 & -2.33 & 0.085 & 1.11 & 0.082 & 1.07 \\
\hline Age2534 & -0.059 & -0.57 & -0.050 & -0.49 & -0.208 & -2.49 & -0.214 & -2.57 & 0.196 & 2.36 & 0.194 & 2.34 \\
\hline Age4554 & -0.095 & -0.90 & -0.080 & -0.77 & -0.048 & -0.56 & -0.052 & -0.61 & 0.337 & 3.95 & 0.336 & 3.95 \\
\hline Age54plus & -0.136 & -1.17 & -0.116 & -1 & -0.042 & -0.44 & -0.047 & -0.5 & 0.484 & 5.07 & 0.482 & 5.06 \\
\hline Educ2 & 0.058 & 0.37 & 0.043 & 0.28 & 0.198 & 1.36 & 0.202 & 1.4 & 0.187 & 1.34 & 0.207 & 1.49 \\
\hline Educ3 & 0.279 & 2.29 & 0.271 & 2.23 & 0.043 & 0.40 & 0.047 & 0.44 & 0.091 & 0.85 & 0.094 & 0.89 \\
\hline Educ4 & 0.314 & 2.89 & 0.314 & 2.89 & 0.031 & 0.32 & 0.036 & 0.37 & 0.005 & 0.05 & 0.005 & 0.05 \\
\hline Educ5 & 0.243 & 2.09 & 0.253 & 2.18 & 0.305 & 2.93 & 0.305 & 2.96 & -0.246 & -2.39 & -0.261 & -2.56 \\
\hline Educ6 & 0.262 & 2.96 & 0.255 & 2.9 & 0.170 & 2.06 & 0.159 & 1.93 & 0.009 & 0.11 & -0.003 & -0.04 \\
\hline Educ7 & 0.197 & 1.38 & 0.224 & 1.59 & 0.333 & 2.60 & 0.344 & 2.74 & -0.211 & -1.69 & -0.238 & -1.92 \\
\hline Educ8 & 0.236 & 1.83 & 0.243 & 1.89 & 0.313 & 2.79 & 0.286 & 2.59 & -0.257 & -2.33 & -0.288 & -2.66 \\
\hline Educ9 & 0.254 & 2.03 & 0.241 & 1.94 & 0.324 & 2.90 & 0.347 & 3.24 & -0.226 & -2.09 & -0.258 & -2.47 \\
\hline Educ10 & 0.206 & 1.48 & 0.217 & 1.58 & 0.293 & 2.41 & 0.356 & 3.13 & -0.501 & -4.17 & -0.538 & -4.77 \\
\hline Child2 & 0.009 & 0.15 & 0.011 & 0.18 & -0.100 & -2.01 & -0.099 & -2 & -0.024 & -0.47 & -0.025 & -0.51 \\
\hline Child3 & -0.023 & -0.36 & -0.021 & -0.34 & 0.023 & 0.44 & 0.024 & 0.47 & -0.006 & -0.12 & -0.008 & -0.15 \\
\hline Child4 & -0.068 & -0.76 & -0.065 & -0.73 & 0.235 & 3.00 & 0.235 & 3.01 & 0.073 & 0.97 & 0.072 & 0.96 \\
\hline Married & -0.095 & -1.58 & -0.100 & -1.68 & -0.120 & -2.49 & -0.119 & -2.46 & 0.104 & 2.18 & 0.105 & 2.21 \\
\hline Widow & -0.188 & -0.97 & -0.194 & -1 & 0.043 & 0.23 & 0.043 & 0.23 & -0.458 & -2.61 & -0.455 & -2.58 \\
\hline Divorced & -0.139 & -1.57 & -0.143 & -1.61 & -0.030 & -0.38 & -0.025 & -0.33 & -0.061 & -0.78 & -0.062 & -0.79 \\
\hline Loghwage & 0.130 & 1.46 & 0.113 & 1.3 & 0.026 & 0.35 & 0.021 & 0.3 & -0.004 & -0.06 & -0.030 & -0.43 \\
\hline Occup2 & -0.182 & -1.18 & -0.171 & -1.12 & 0.112 & 0.92 & & & -0.049 & -0.42 & & \\
\hline
\end{tabular}




\begin{tabular}{|c|c|c|c|c|c|c|c|c|c|c|c|c|}
\hline Occup3 & -0.326 & -2.31 & -0.332 & -2.35 & -0.052 & -0.47 & & & -0.054 & -0.50 & & \\
\hline Occup4 & -0.244 & -1.76 & -0.251 & -1.81 & -0.007 & -0.06 & & & 0.005 & 0.04 & & \\
\hline Occup5 & -0.310 & -2.03 & -0.320 & -2.09 & 0.071 & 0.58 & & & 0.102 & 0.84 & & \\
\hline Occup6 & -0.401 & -2.78 & -0.397 & -2.75 & -0.031 & -0.26 & & & 0.028 & 0.25 & & \\
\hline Sect 2 & -0.087 & -1.13 & & & -0.134 & -2.03 & & & 0.095 & 1.42 & 0.106 & 1.61 \\
\hline Sect 3 & -0.023 & -0.38 & & & 0.033 & 0.65 & & & 0.110 & 2.14 & 0.111 & 2.29 \\
\hline Sect 4 & 0.034 & 0.48 & & & 0.023 & 0.38 & & & -0.031 & -0.51 & -0.027 & -0.46 \\
\hline Sect5 & -0.023 & -0.34 & & & -0.011 & -0.19 & & & -0.103 & -1.82 & -0.112 & -2.09 \\
\hline Sect6 & 0.107 & 1.25 & & & 0.036 & 0.52 & & & 0.043 & 0.62 & 0.040 & 0.59 \\
\hline Size1 & 0.039 & 0.48 & & & -0.005 & -0.07 & & & -0.016 & -0.24 & & \\
\hline Size2 & 0.051 & 0.70 & & & 0.057 & 0.95 & & & -0.005 & -0.09 & & \\
\hline Size3 & 0.109 & 1.33 & & & -0.042 & -0.63 & & & -0.020 & -0.29 & & \\
\hline Size4 & -0.002 & -0.03 & & & 0.030 & 0.52 & & & -0.014 & -0.23 & & \\
\hline $\operatorname{Reg} 2$ & -0.068 & -1.27 & & & 0.005 & 0.10 & & & 0.040 & 0.89 & & \\
\hline $\operatorname{Reg} 3$ & -0.002 & -0.03 & & & 0.008 & 0.16 & & & -0.024 & -0.50 & & \\
\hline Y05 & -0.344 & -7.97 & -0.341 & -7.95 & 0.065 & 1.82 & 0.059 & 1.68 & -0.510 & -14.48 & -0.510 & -14.61 \\
\hline cons & 1.202 & 2.37 & 1.282 & 2.630 & 0.644 & 1.52 & 0.699 & 1.91 & 0.489 & 1.16 & 0.627 & 1.69 \\
\hline
\end{tabular}

Test joint insignificance variables excluded in (iii) p-value:

$\begin{array}{ll}0.52 & 0.79\end{array}$ 0.42

Note: the p-values of the joint insignificance tests are computed from a chi2 with 11 degrees of freedom for SAH and MH, and with 16 degrees of freedom for $\mathrm{PH}$ 
Table A3. Multivariate Probit coefficients' estimates for self-assessed health ( $S A H)$

\begin{tabular}{|c|c|c|c|c|c|c|c|c|c|c|c|c|c|c|c|c|}
\hline \multirow{3}{*}{$\underline{D e p .} \operatorname{Var}(s)$} & \multicolumn{16}{|c|}{ MULTIVARIATE PROBIT (with exclusion restrictions) } \\
\hline & \multicolumn{2}{|c|}{$\underline{S A H}$} & \multicolumn{2}{|c|}{ Smoker } & \multicolumn{2}{|c|}{ Drinker } & \multicolumn{2}{|c|}{ Obese } & \multicolumn{2}{|c|}{ Phys. hazards } & \multicolumn{2}{|c|}{$\frac{\text { No supp from }}{\text { colleag }}$} & \multicolumn{2}{|c|}{ Repetit. work } & \multicolumn{2}{|c|}{$\underline{\text { Job worries }}$} \\
\hline & Coef. & $z$ & Coef. & $z$ & Coef. & $z$ & Coef. & $z$ & Coef. & $z$ & Coef. & $z$ & Coef. & $z$ & Coef. & $z$ \\
\hline Smoker & -0.146 & -0.64 & & & & & & & & & & & & & & \\
\hline Drinker & -0.701 & -2.88 & & & & & & & & & & & & & & \\
\hline Obese & -0.611 & -2.38 & & & & & & & & & & & & & & \\
\hline Phys. hazards & -0.386 & -2.07 & & & & & & & & & & & & & & \\
\hline No supp. from colleagues & -0.671 & -3.76 & & & & & & & & & & & & & & \\
\hline Job worries & -0.510 & -2.8 & & & & & & & & & & & & & & \\
\hline Repetitive. work & -0.082 & -0.4 & & & & & & & & & & & & & & \\
\hline Female & 0.049 & 0.97 & -0.106 & -2.71 & -0.225 & -4.53 & -0.039 & -0.79 & -0.138 & -3.63 & -0.095 & -2.52 & 0.297 & 7.63 & 0.076 & 2 \\
\hline Ageless 25 & 0.075 & 0.77 & 0.220 & 2.82 & -0.298 & -2.94 & 0.547 & 4.6 & -0.078 & -0.98 & -0.027 & -0.34 & -0.111 & -1.39 & 0.168 & 2.12 \\
\hline Age2534 & 0.045 & 0.42 & 0.309 & 3.7 & 0.009 & 0.09 & 0.762 & 6.18 & -0.132 & -1.55 & 0.191 & 2.29 & -0.079 & -0.92 & 0.438 & 5.18 \\
\hline Age4554 & 0.074 & 0.65 & 0.297 & 3.46 & 0.306 & 2.85 & 0.654 & 5.2 & -0.181 & -2.08 & 0.233 & 2.73 & -0.065 & -0.74 & 0.671 & 7.76 \\
\hline Age54plus & 0.085 & 0.66 & 0.244 & 2.56 & 0.476 & 4.09 & 0.649 & 4.78 & -0.464 & -4.85 & 0.326 & 3.47 & 0.047 & 0.48 & 0.730 & 7.67 \\
\hline Educ2 & 0.078 & 0.52 & 0.046 & 0.32 & 0.058 & 0.31 & 0.043 & 0.25 & 0.152 & 0.97 & 0.077 & 0.54 & -0.053 & -0.31 & 0.052 & 0.37 \\
\hline Educ3 & 0.258 & 2.19 & 0.198 & 1.93 & 0.291 & 2.22 & 0.123 & 1.01 & 0.021 & 0.19 & -0.201 & -1.91 & -0.162 & -1.39 & -0.025 & -0.25 \\
\hline Educ4 & 0.327 & 3.08 & -0.022 & -0.23 & 0.370 & 3.14 & 0.020 & 0.18 & -0.074 & -0.77 & -0.105 & -1.11 & -0.323 & -3.09 & 0.106 & 1.15 \\
\hline Educ5 & 0.235 & 1.97 & -0.149 & -1.48 & 0.252 & 1.93 & 0.024 & 0.19 & -0.300 & -2.93 & -0.103 & -1.02 & -0.506 & -4.62 & -0.151 & -1.5 \\
\hline Educ6 & 0.267 & 2.92 & -0.140 & -1.77 & 0.291 & 2.94 & -0.099 & -1.05 & -0.134 & -1.65 & 0.037 & 0.47 & -0.484 & -5.39 & -0.162 & -2.07 \\
\hline Educ7 & 0.219 & 1.48 & -0.431 & -3.37 & 0.327 & 2.07 & -0.379 & -2.28 & -0.153 & -1.26 & -0.024 & -0.2 & -0.642 & -5.04 & -0.270 & -2.2 \\
\hline Educ8 & 0.289 & 2.14 & -0.501 & -4.42 & 0.380 & 2.83 & -0.225 & -1.65 & -0.329 & -3.04 & 0.161 & 1.51 & -0.786 & -6.84 & -0.155 & -1.45 \\
\hline Educ9 & 0.271 & 1.98 & -0.523 & -4.76 & 0.290 & 2.18 & -0.320 & -2.35 & -0.399 & -3.77 & 0.166 & 1.59 & -0.874 & -7.69 & -0.252 & -2.38 \\
\hline Educ10 & 0.223 & 1.47 & -0.830 & -6.49 & 0.323 & 2.21 & -0.629 & -3.74 & -0.558 & -4.84 & 0.050 & 0.44 & -0.849 & -6.91 & -0.114 & -1.0 \\
\hline Child2 & -0.001 & -0.02 & 0.021 & 0.42 & -0.221 & -3.46 & -0.071 & -1.14 & -0.016 & -0.32 & 0.084 & 1.73 & 0.026 & 0.52 & 0.013 & 0.26 \\
\hline Child3 & -0.047 & -0.78 & -0.033 & -0.63 & -0.156 & -2.39 & -0.178 & -2.7 & -0.049 & -0.96 & 0.035 & 0.69 & -0.002 & -0.03 & -0.051 & -1.00 \\
\hline Child4 & -0.110 & -1.29 & -0.089 & -1.16 & -0.362 & -3.57 & -0.095 & -1.04 & -0.134 & -1.81 & 0.068 & 0.94 & -0.058 & -0.78 & -0.187 & -2.51 \\
\hline Married & -0.105 & -1.87 & -0.182 & -3.78 & -0.003 & -0.05 & 0.095 & 1.58 & -0.076 & -1.60 & -0.074 & -1.59 & -0.061 & -1.27 & 0.006 & 0.12 \\
\hline
\end{tabular}




\begin{tabular}{|c|c|c|c|c|c|c|c|c|c|c|c|c|c|c|c|c|}
\hline Widow & -0.227 & -1.17 & -0.234 & -1.3 & 0.038 & 0.18 & -0.039 & -0.18 & 0.099 & 0.56 & -0.407 & -2.23 & -0.246 & -1.35 & 0.014 & 0.08 \\
\hline Divorced & -0.131 & -1.48 & 0.264 & 3.55 & 0.172 & 1.89 & 0.008 & 0.08 & -0.004 & -0.05 & -0.110 & -1.47 & 0.140 & 1.8 & 0.005 & 0.07 \\
\hline Loghwage & 0.064 & 0.65 & -0.018 & -0.23 & 0.218 & 2.42 & -0.178 & -1.9 & -0.262 & -3.62 & -0.129 & -1.8 & -0.667 & -9.03 & -0.345 & -4.71 \\
\hline Occup2 & -0.177 & -1.16 & -0.168 & -1.36 & 0.058 & 0.39 & 0.095 & 0.57 & 0.154 & 1.35 & -0.207 & -1.83 & 0.097 & 0.81 & 0.052 & 0.44 \\
\hline Occup3 & -0.286 & -2 & -0.166 & -1.49 & 0.118 & 0.86 & 0.169 & 1.15 & 0.178 & 1.69 & -0.072 & -0.69 & 0.235 & 2.14 & 0.084 & 0.77 \\
\hline Occup4 & -0.193 & -1.29 & 0.000 & 0 & 0.119 & 0.88 & 0.099 & 0.69 & 0.539 & 5.18 & -0.113 & -1.1 & 0.550 & 5.12 & 0.106 & 0.99 \\
\hline Occup5 & -0.220 & -1.32 & 0.248 & 2.03 & 0.338 & 2.26 & 0.220 & 1.39 & 0.741 & 6.13 & -0.120 & -1.02 & 0.790 & 6.35 & 0.122 & 1.01 \\
\hline Occup6 & -0.325 & -2.19 & 0.085 & 0.73 & 0.224 & 1.57 & 0.066 & 0.43 & 0.352 & 3.17 & -0.054 & -0.5 & 0.471 & 4.11 & -0.041 & -0.35 \\
\hline Sect 2 & & & -0.053 & -0.8 & 0.246 & 3.2 & 0.069 & 0.84 & 0.202 & 2.96 & 0.127 & 2 & 0.155 & 2.29 & -0.280 & -4.15 \\
\hline Sect 3 & & & -0.172 & -3.34 & -0.119 & -1.82 & 0.067 & 1.04 & -0.192 & -3.82 & -0.086 & -1.72 & -0.104 & -2.01 & -0.086 & -1.7 \\
\hline Sect 4 & & & 0.018 & 0.3 & -0.005 & -0.07 & 0.239 & 3.37 & 0.087 & 1.45 & 0.125 & 2.17 & 0.074 & 1.19 & -0.082 & -1.4 \\
\hline Sect5 & & & -0.179 & -3.08 & -0.064 & -0.9 & -0.065 & -0.87 & -0.277 & -5.09 & -0.048 & -0.88 & -0.135 & -2.41 & -0.060 & -1.09 \\
\hline Sect6 & & & 0.020 & 0.28 & 0.110 & 1.31 & -0.096 & -1.03 & 0.217 & 3.17 & -0.177 & -2.62 & -0.208 & -3.01 & -0.176 & -2.6 \\
\hline Size1 & & & 0.123 & 1.79 & 0.229 & 2.76 & 0.006 & 0.07 & -0.209 & -3.14 & 0.241 & 3.69 & -0.120 & -1.77 & -0.220 & -3.35 \\
\hline Size2 & & & 0.037 & 0.61 & 0.140 & 1.87 & -0.152 & -2.02 & -0.136 & -2.31 & 0.089 & 1.54 & -0.056 & -0.94 & -0.215 & -3.71 \\
\hline Size3 & & & 0.089 & 1.29 & 0.016 & 0.19 & -0.118 & -1.39 & -0.060 & -0.89 & 0.086 & 1.31 & -0.076 & -1.11 & -0.046 & -0.7 \\
\hline Size4 & & & 0.088 & 1.46 & 0.035 & 0.46 & -0.015 & -0.21 & -0.050 & -0.86 & 0.068 & 1.2 & -0.019 & -0.31 & 0.003 & 0.04 \\
\hline Reg2 & & & -0.067 & -1.5 & -0.156 & -2.92 & 0.114 & 2.03 & -0.043 & -0.98 & -0.029 & -0.68 & -0.002 & -0.04 & 0.023 & 0.54 \\
\hline Reg3 & & & -0.093 & -1.96 & -0.258 & -4.47 & 0.067 & 1.12 & -0.052 & -1.14 & -0.075 & -1.68 & -0.038 & -0.82 & -0.022 & -0.48 \\
\hline Y05 & -0.275 & -4.46 & -0.221 & -6.09 & -0.312 & -6.92 & 0.128 & 2.76 & -0.035 & -0.98 & 0.389 & 10.84 & 0.139 & 3.8 & -0.044 & -1.22 \\
\hline cons & 1.729 & 2.88 & -0.097 & -0.23 & -2.400 & -4.71 & -1.010 & -1.91 & 1.858 & 4.56 & 0.055 & 0.13 & 3.705 & 8.9 & 1.238 & 3.01 \\
\hline
\end{tabular}


Table A4. Multivariate Probit coefficients' estimates for physical health $(P H)$

\begin{tabular}{|c|c|c|c|c|c|c|c|c|c|c|c|c|c|c|c|c|}
\hline \multirow{3}{*}{$\underline{\operatorname{Dep} . \operatorname{Var}(s)}$} & \multicolumn{16}{|c|}{ MULTIVARIATE PROBIT (with exclusion restrictions.) } \\
\hline & \multicolumn{2}{|c|}{$\underline{P H}$} & \multicolumn{2}{|c|}{ Smoker } & \multicolumn{2}{|c|}{ Drinker } & \multicolumn{2}{|c|}{ Obese } & \multicolumn{2}{|c|}{ Phys. hazards } & \multicolumn{2}{|c|}{ No supp from colleag } & \multicolumn{2}{|c|}{$\underline{\text { Repetit. work }}$} & \multicolumn{2}{|c|}{ Job worries } \\
\hline & Coef. & $z$ & Coef. & $z$ & Coef. & $z$ & Coef. & $z$ & Coef. & $z$ & Coef. & $z$ & Coef. & $z$ & Coef. & $z$ \\
\hline Smoker & 0.100 & 0.40 & & & & & & & & & & & & & & \\
\hline Drinker & -0.012 & -0.04 & & & & & & & & & & & & & & \\
\hline Obese & -0.147 & -0.48 & & & & & & & & & & & & & & \\
\hline Phys. hazards & -0.375 & -2.12 & & & & & & & & & & & & & & \\
\hline No supp. from colleagues & -0.603 & -3.26 & & & & & & & & & & & & & & \\
\hline Job worries & -0.415 & -2.11 & & & & & & & & & & & & & & \\
\hline Repetitive work & -0.303 & -1.41 & & & & & & & & & & & & & & \\
\hline Female & -0.206 & -4.20 & -0.106 & -2.70 & -0.220 & -4.41 & -0.04 & -0.820 & -0.138 & -3.63 & -0.098 & -2.58 & 0.298 & 7.65 & 0.075 & 1.96 \\
\hline Ageless 25 & -0.186 & -2.26 & 0.221 & 2.85 & -0.296 & -2.91 & 0.54 & 4.510 & -0.080 & -1.01 & -0.040 & -0.52 & -0.114 & -1.43 & 0.162 & 2.05 \\
\hline Age2534 & -0.147 & -1.46 & 0.311 & 3.72 & 0.019 & 0.17 & 0.76 & 6.090 & -0.132 & -1.56 & 0.179 & 2.16 & -0.081 & -0.94 & 0.433 & 5.12 \\
\hline Age4554 & 0.040 & 0.36 & 0.297 & 3.47 & 0.306 & 2.84 & 0.65 & 5.120 & -0.182 & -2.09 & 0.222 & 2.63 & -0.067 & -0.76 & 0.665 & 7.70 \\
\hline Age54plus & 0.079 & 0.61 & 0.244 & 2.56 & 0.476 & 4.08 & 0.64 & 4.720 & -0.467 & -4.88 & 0.313 & 3.35 & 0.044 & 0.45 & 0.723 & 7.61 \\
\hline Educ2 & 0.209 & 1.49 & 0.046 & 0.32 & 0.068 & 0.36 & 0.05 & 0.280 & 0.157 & 1.00 & 0.077 & 0.53 & -0.053 & -0.31 & 0.050 & 0.35 \\
\hline Educ3 & -0.031 & -0.29 & 0.198 & 1.93 & 0.308 & 2.33 & 0.12 & 1.010 & 0.019 & 0.17 & -0.210 & -2.00 & -0.159 & -1.36 & -0.029 & -0.28 \\
\hline Educ4 & 0.003 & 0.03 & -0.020 & -0.22 & 0.386 & 3.24 & 0.02 & 0.180 & -0.074 & -0.76 & -0.113 & -1.20 & -0.319 & -3.05 & 0.101 & 1.09 \\
\hline Educ5 & 0.220 & 2.04 & -0.146 & -1.45 & 0.269 & 2.04 & 0.02 & 0.150 & -0.300 & -2.93 & -0.117 & -1.16 & -0.504 & -4.60 & -0.157 & -1.56 \\
\hline Educ6 & 0.121 & 1.40 & -0.138 & -1.74 & 0.309 & 3.09 & -0.10 & -1.040 & -0.135 & -1.66 & 0.031 & 0.39 & -0.481 & -5.37 & -0.167 & -2.13 \\
\hline Educ7 & 0.260 & 1.92 & -0.432 & -3.38 & 0.356 & 2.24 & -0.38 & -2.260 & -0.152 & -1.25 & -0.026 & -0.22 & -0.639 & -5.02 & -0.276 & -2.25 \\
\hline Educ8 & 0.265 & 2.06 & -0.503 & -4.43 & 0.395 & 2.93 & -0.23 & -1.670 & -0.331 & -3.06 & 0.145 & 1.36 & -0.786 & -6.85 & -0.164 & -1.53 \\
\hline Educ9 & 0.299 & 2.31 & -0.524 & -4.78 & 0.307 & 2.28 & -0.33 & -2.380 & -0.399 & -3.77 & 0.160 & 1.54 & -0.871 & -7.67 & -0.253 & -2.40 \\
\hline Educ10 & 0.291 & 2.09 & -0.829 & -6.50 & 0.327 & 2.21 & -0.63 & -3.740 & -0.557 & -4.82 & 0.044 & 0.38 & -0.846 & -6.89 & -0.115 & -1.00 \\
\hline Child2 & -0.079 & -1.60 & 0.018 & 0.36 & -0.217 & -3.39 & -0.07 & -1.120 & -0.017 & -0.34 & 0.086 & 1.77 & 0.025 & 0.51 & 0.012 & 0.25 \\
\hline Child3 & 0.022 & 0.42 & -0.035 & -0.66 & -0.161 & -2.46 & -0.18 & -2.680 & -0.051 & -0.99 & 0.030 & 0.58 & -0.004 & -0.09 & -0.052 & -1.03 \\
\hline Child4 & 0.211 & 2.70 & -0.089 & -1.16 & -0.361 & -3.55 & -0.09 & -1.020 & -0.135 & -1.82 & 0.069 & 0.95 & -0.059 & -0.80 & -0.187 & -2.52 \\
\hline Married & -0.115 & -2.36 & -0.183 & -3.82 & -0.001 & -0.02 & 0.10 & 1.590 & -0.075 & -1.58 & -0.075 & -1.61 & -0.060 & -1.26 & 0.007 & 0.15 \\
\hline
\end{tabular}




\begin{tabular}{|c|c|c|c|c|c|c|c|c|c|c|c|c|c|c|c|c|}
\hline Widow & -0.031 & -0.18 & -0.238 & -1.32 & 0.053 & 0.26 & -0.05 & -0.210 & 0.102 & 0.57 & -0.419 & -2.28 & -0.239 & -1.30 & 0.023 & 0.13 \\
\hline Divorced & -0.070 & -0.88 & 0.262 & 3.52 & 0.160 & 1.74 & 0.01 & 0.060 & -0.003 & -0.04 & -0.115 & -1.54 & 0.139 & 1.79 & 0.007 & 0.09 \\
\hline Loghwage & -0.100 & -1.15 & -0.017 & -0.22 & 0.220 & 2.42 & -0.18 & -1.950 & -0.263 & -3.63 & -0.136 & -1.89 & -0.666 & -9.03 & -0.349 & -4.77 \\
\hline Occup2 & & & -0.158 & -1.28 & 0.060 & 0.40 & 0.09 & 0.540 & 0.147 & 1.29 & -0.225 & -2.03 & 0.088 & 0.73 & 0.043 & 0.36 \\
\hline Occup3 & & & -0.165 & -1.48 & 0.121 & 0.88 & 0.17 & 1.160 & 0.178 & 1.68 & -0.067 & -0.65 & 0.233 & 2.13 & 0.088 & 0.81 \\
\hline Occup4 & & & 0.004 & 0.04 & 0.105 & 0.78 & 0.10 & 0.670 & 0.535 & 5.15 & -0.118 & -1.17 & 0.544 & 5.08 & 0.101 & 0.95 \\
\hline Occup5 & & & 0.257 & 2.12 & 0.320 & 2.13 & 0.22 & 1.380 & 0.735 & 6.06 & -0.141 & -1.22 & 0.775 & 6.21 & 0.111 & 0.93 \\
\hline Occup6 & & & 0.086 & 0.75 & 0.214 & 1.50 & 0.06 & 0.410 & 0.349 & 3.14 & -0.057 & -0.53 & 0.469 & 4.11 & -0.040 & -0.35 \\
\hline Sect 2 & & & -0.065 & -0.98 & 0.251 & 3.21 & 0.07 & 0.820 & 0.205 & 2.99 & 0.144 & 2.29 & 0.162 & 2.39 & -0.270 & -3.97 \\
\hline Sect 3 & & & -0.174 & -3.40 & -0.122 & -1.84 & 0.06 & 0.980 & -0.196 & -3.91 & -0.104 & -2.11 & -0.104 & -2.02 & -0.093 & -1.85 \\
\hline Sect 4 & & & 0.021 & 0.36 & 0.011 & 0.14 & 0.24 & 3.410 & 0.090 & 1.49 & 0.121 & 2.12 & 0.071 & 1.15 & -0.084 & -1.43 \\
\hline Sect5 & & & -0.183 & -3.16 & -0.072 & -1.01 & -0.07 & -0.880 & -0.278 & -5.11 & -0.054 & -1.02 & -0.132 & -2.37 & -0.062 & -1.13 \\
\hline Sect6 & & & 0.017 & 0.24 & 0.121 & 1.43 & -0.09 & -0.960 & 0.222 & 3.24 & -0.166 & -2.48 & -0.208 & -3.02 & -0.171 & -2.51 \\
\hline Size1 & & & 0.124 & 1.81 & 0.236 & 2.81 & 0.01 & 0.080 & -0.204 & -3.07 & 0.249 & 3.86 & -0.119 & -1.76 & -0.216 & -3.30 \\
\hline Size2 & & & 0.042 & 0.69 & 0.145 & 1.91 & -0.15 & -2.000 & -0.135 & -2.29 & 0.088 & 1.53 & -0.058 & -0.97 & -0.216 & -3.74 \\
\hline Size3 & & & 0.083 & 1.21 & 0.016 & 0.18 & -0.11 & -1.350 & -0.051 & -0.76 & 0.112 & 1.74 & -0.069 & -1.01 & -0.035 & -0.53 \\
\hline Size4 & & & 0.092 & 1.54 & 0.032 & 0.43 & -0.02 & -0.210 & -0.051 & -0.88 & 0.062 & 1.11 & -0.020 & -0.34 & -0.003 & -0.06 \\
\hline Reg2 & & & -0.066 & -1.50 & -0.162 & -3.01 & 0.11 & 1.970 & -0.047 & -1.08 & -0.045 & -1.08 & -0.004 & -0.09 & 0.016 & 0.38 \\
\hline Reg3 & & & -0.093 & -1.98 & -0.257 & -4.39 & 0.06 & 1.070 & -0.053 & -1.16 & -0.081 & -1.83 & -0.039 & -0.84 & -0.024 & -0.53 \\
\hline Y05 & 0.163 & 3.15 & -0.221 & -6.12 & -0.317 & -7.02 & 0.13 & 2.750 & -0.037 & -1.02 & 0.384 & 10.70 & 0.137 & 3.75 & -0.045 & -1.26 \\
\hline cons & 1.580 & 2.95 & -0.106 & -0.25 & -2.418 & -4.72 & -0.98 & -1.850 & 1.869 & 4.58 & 0.126 & 0.31 & 3.711 & 8.92 & 1.275 & 3.10 \\
\hline
\end{tabular}


Table A5. Multivariate Probit coefficients' estimates for mental health $(M H)$

\begin{tabular}{|c|c|c|c|c|c|c|c|c|c|c|c|c|c|c|c|c|}
\hline \multirow{3}{*}{$\underline{\operatorname{Dep}} \cdot \operatorname{Var}(s)$} & \multicolumn{16}{|c|}{ MULTIVARIATE PROBIT (with exclusion restrictions.) } \\
\hline & \multicolumn{2}{|c|}{$\underline{M H}$} & \multicolumn{2}{|c|}{$\underline{\text { Smoker }}$} & \multicolumn{2}{|c|}{ Drinker } & \multicolumn{2}{|c|}{ Obese } & \multicolumn{2}{|c|}{ Phys. hazards } & \multicolumn{2}{|c|}{ No supp from colleag } & \multicolumn{2}{|c|}{ Repetit. work } & \multicolumn{2}{|c|}{ Job worries } \\
\hline & Coef. & $z$ & Coef. & $z$ & Coef. & $z$ & Coef. & $z$ & Coef. & $z$ & Coef. & $z$ & Coef. & $z$ & Coef. & $z$ \\
\hline Smoker & 0.476 & 2.45 & & & & & & & & & & & & & & \\
\hline Drinker & -0.153 & -0.63 & & & & & & & & & & & & & & \\
\hline Obese & -0.475 & -1.8 & & & & & & & & & & & & & & \\
\hline Phys. hazards & -0.618 & -3.7 & & & & & & & & & & & & & & \\
\hline No supp. from colleagues & -0.576 & -2.83 & & & & & & & & & & & & & & \\
\hline Job worries & -0.352 & -1.87 & & & & & & & & & & & & & & \\
\hline Repetitive. work & 0.278 & 1.47 & & & & & & & & & & & & & & \\
\hline Female & -0.264 & -5.69 & -0.105 & -2.69 & -0.219 & -4.39 & -0.042 & -0.85 & -0.140 & -3.7 & -0.098 & -2.57 & 0.299 & 7.68 & 0.074 & 1.95 \\
\hline Ageless 25 & 0.065 & 0.81 & 0.222 & 2.86 & -0.297 & -2.92 & 0.547 & 4.61 & -0.082 & -1.02 & -0.040 & -0.51 & -0.115 & -1.44 & 0.164 & 2.06 \\
\hline Age2534 & 0.183 & 1.92 & 0.309 & 3.7 & 0.017 & 0.16 & 0.763 & 6.19 & -0.133 & -1.57 & 0.184 & 2.22 & -0.086 & -1 & 0.436 & 5.15 \\
\hline Age4554 & 0.302 & 2.84 & 0.294 & 3.44 & 0.305 & 2.83 & 0.650 & 5.17 & -0.182 & -2.09 & 0.229 & 2.7 & -0.071 & -0.8 & 0.667 & 7.72 \\
\hline Age54plus & 0.396 & 3.18 & 0.245 & 2.57 & 0.475 & 4.07 & 0.647 & 4.77 & -0.466 & -4.87 & 0.320 & 3.41 & 0.040 & 0.41 & 0.726 & 7.63 \\
\hline Educ2 & 0.223 & 1.58 & 0.043 & 0.3 & 0.067 & 0.36 & 0.043 & 0.26 & 0.163 & 1.04 & 0.073 & 0.51 & -0.050 & -0.29 & 0.053 & 0.37 \\
\hline Educ3 & 0.046 & 0.43 & 0.193 & 1.88 & 0.308 & 2.33 & 0.120 & 0.98 & 0.030 & 0.28 & -0.211 & -2.01 & -0.169 & -1.45 & -0.030 & -0.29 \\
\hline Educ4 & 0.021 & 0.22 & -0.024 & -0.25 & 0.385 & 3.23 & 0.020 & 0.18 & -0.065 & -0.68 & -0.111 & -1.17 & -0.321 & -3.08 & 0.105 & 1.14 \\
\hline Educ5 & -0.207 & -1.92 & -0.144 & -1.43 & 0.270 & 2.04 & 0.027 & 0.22 & -0.299 & -2.93 & -0.113 & -1.11 & -0.505 & -4.61 & -0.153 & -1.52 \\
\hline Educ6 & 0.064 & 0.76 & -0.141 & -1.79 & 0.309 & 3.09 & -0.103 & -1.09 & -0.130 & -1.6 & 0.034 & 0.43 & -0.484 & -5.41 & -0.163 & -2.08 \\
\hline Educ7 & -0.107 & -0.8 & -0.431 & -3.38 & 0.353 & 2.23 & -0.374 & -2.26 & -0.149 & -1.23 & -0.032 & -0.26 & -0.641 & -5.05 & -0.268 & -2.18 \\
\hline Educ8 & -0.113 & -0.88 & -0.499 & -4.42 & 0.395 & 2.92 & -0.231 & -1.69 & -0.325 & -3.01 & 0.157 & 1.46 & -0.785 & -6.84 & -0.155 & -1.45 \\
\hline Educ9 & -0.094 & -0.73 & -0.523 & -4.78 & 0.306 & 2.28 & -0.336 & -2.46 & -0.399 & -3.78 & 0.156 & 1.5 & -0.870 & -7.66 & -0.254 & -2.4 \\
\hline Educ10 & -0.380 & -2.68 & -0.830 & -6.5 & 0.328 & 2.22 & -0.637 & -3.8 & -0.559 & -4.86 & 0.038 & 0.33 & -0.844 & -6.88 & -0.115 & -1.01 \\
\hline Child2 & -0.024 & -0.49 & 0.022 & 0.44 & -0.216 & -3.38 & -0.065 & -1.04 & -0.018 & -0.36 & 0.084 & 1.72 & 0.025 & 0.5 & 0.012 & 0.24 \\
\hline Child3 & -0.017 & -0.32 & -0.034 & -0.65 & -0.162 & -2.47 & -0.183 & -2.77 & -0.049 & -0.96 & 0.033 & 0.65 & -0.002 & -0.03 & -0.051 & -1 \\
\hline Child4 & 0.071 & 0.94 & -0.090 & -1.18 & -0.361 & -3.56 & -0.097 & -1.06 & -0.136 & -1.83 & 0.075 & 1.02 & -0.056 & -0.75 & -0.186 & -2.5 \\
\hline Married & 0.118 & 2.46 & -0.178 & -3.71 & -0.001 & -0.02 & 0.097 & 1.63 & -0.075 & -1.59 & -0.079 & -1.69 & -0.061 & -1.27 & 0.006 & 0.13 \\
\hline
\end{tabular}




\begin{tabular}{|c|c|c|c|c|c|c|c|c|c|c|c|c|c|c|c|c|}
\hline Widow & -0.380 & -2.14 & -0.241 & -1.33 & 0.052 & 0.26 & -0.040 & -0.18 & 0.104 & 0.59 & -0.423 & -2.31 & -0.240 & -1.32 & 0.019 & 0.11 \\
\hline Divorced & -0.140 & -1.84 & 0.268 & 3.59 & 0.160 & 1.75 & 0.001 & 0.02 & -0.004 & -0.05 & -0.121 & -1.61 & 0.144 & 1.86 & 0.005 & 0.07 \\
\hline Loghwage & -0.011 & -0.12 & -0.016 & -0.21 & 0.222 & 2.44 & -0.174 & -1.85 & -0.266 & -3.69 & -0.138 & -1.92 & -0.658 & -8.92 & -0.348 & -4.75 \\
\hline Occup2 & & & -0.178 & -1.47 & 0.060 & 0.4 & 0.095 & 0.58 & 0.155 & 1.37 & -0.205 & -1.82 & 0.093 & 0.78 & 0.052 & 0.44 \\
\hline Occup3 & & & -0.174 & -1.59 & 0.121 & 0.88 & 0.174 & 1.18 & 0.177 & 1.7 & -0.069 & -0.67 & 0.236 & 2.16 & 0.084 & 0.77 \\
\hline Occup4 & & & -0.002 & -0.02 & 0.105 & 0.78 & 0.099 & 0.69 & 0.532 & 5.18 & -0.113 & -1.1 & 0.555 & 5.18 & 0.104 & 0.97 \\
\hline Occup5 & & & 0.256 & 2.14 & 0.323 & 2.15 & 0.212 & 1.34 & 0.723 & 6.02 & -0.127 & -1.08 & 0.798 & 6.44 & 0.120 & 1 \\
\hline Occup6 & & & 0.081 & 0.71 & 0.214 & 1.5 & 0.067 & 0.44 & 0.345 & 3.15 & -0.058 & -0.53 & 0.476 & 4.17 & -0.043 & -0.37 \\
\hline Sect 2 & 0.134 & 1.93 & -0.052 & -0.79 & 0.250 & 3.22 & 0.058 & 0.7 & 0.197 & 2.89 & 0.119 & 1.84 & 0.158 & 2.34 & -0.282 & -4.17 \\
\hline Sect3 & 0.098 & 1.85 & -0.173 & -3.37 & -0.121 & -1.83 & 0.057 & 0.88 & -0.200 & -3.97 & -0.102 & -2.03 & -0.102 & -1.97 & -0.092 & -1.83 \\
\hline Sect 4 & 0.015 & 0.25 & 0.016 & 0.27 & 0.012 & 0.16 & 0.239 & 3.4 & 0.091 & 1.51 & 0.137 & 2.35 & 0.070 & 1.13 & -0.077 & -1.3 \\
\hline Sect5 & -0.116 & -2.01 & -0.176 & -3.05 & -0.071 & -1 & -0.076 & -1.02 & -0.283 & -5.22 & -0.059 & -1.08 & -0.134 & -2.4 & -0.065 & -1.18 \\
\hline Sect6 & 0.066 & 0.95 & 0.014 & 0.19 & 0.122 & 1.44 & -0.103 & -1.11 & 0.220 & 3.22 & -0.167 & -2.44 & -0.205 & -2.98 & -0.169 & -2.48 \\
\hline Size1 & & & 0.126 & 1.87 & 0.236 & 2.82 & 0.017 & 0.2 & -0.197 & -2.98 & 0.256 & 3.94 & -0.122 & -1.81 & -0.213 & -3.23 \\
\hline Size2 & & & 0.043 & 0.72 & 0.146 & 1.94 & -0.143 & -1.9 & -0.130 & -2.24 & 0.100 & 1.73 & -0.058 & -0.97 & -0.211 & -3.63 \\
\hline Size3 & & & 0.088 & 1.3 & 0.015 & 0.17 & -0.109 & -1.28 & -0.053 & -0.79 & 0.106 & 1.62 & -0.079 & -1.16 & -0.038 & -0.58 \\
\hline Size4 & & & 0.090 & 1.53 & 0.033 & 0.44 & -0.008 & -0.11 & -0.052 & -0.9 & 0.074 & 1.29 & -0.020 & -0.34 & 0.003 & 0.05 \\
\hline Reg2 & & & -0.062 & -1.42 & -0.162 & -3 & 0.106 & 1.9 & -0.055 & -1.27 & -0.049 & -1.16 & 0.002 & 0.04 & 0.017 & 0.38 \\
\hline Reg3 & & & -0.102 & -2.19 & -0.258 & -4.41 & 0.063 & 1.06 & -0.051 & -1.13 & -0.082 & -1.83 & -0.040 & -0.86 & -0.025 & -0.54 \\
\hline Y05 & -0.382 & -6.77 & -0.219 & -6.05 & -0.317 & -7.03 & 0.129 & 2.8 & -0.037 & -1.03 & 0.391 & 10.86 & 0.138 & 3.77 & -0.045 & -1.27 \\
\hline cons & 0.472 & 0.76 & -0.107 & -0.26 & -2.427 & -4.74 & -1.028 & -1.95 & 1.888 & 4.66 & 0.119 & 0.29 & 3.662 & 8.81 & 1.261 & 3.06 \\
\hline
\end{tabular}




\section{References}

Balia, S. and Jones, A.M. 2008. "Mortality, lifestyle and socio-economic status." Journal of Health Economics 27: 1-26.

Bevan, S., Quadrello, T., McGee, R., Mahdon, M., Vavrovsky A. and Barham L. 2009. Fit for work? Musculoskletal disorders in the European Workforce. The Work Foundation.

Bingley, P. and Westergaard-Nielsen, N. 2003. "Returns to tenure, firm-specific human capital and worker heterogeneity." International Journal of Manpower 24: 744-788.

Bhui, K. 2002. Physical activity and stress. In Stress and the Heart. Psychosocial Pathways to Coronary Heart Disease, edited by Stansfeld, M.S. and Marmot, M.. London: BMJ Books.

Blaylock, J. and Blisard, W. 1992. "Self-evaluated health status and smoking behaviour." Applied Economics 24: 429-435.

Bockerman, P. and Illmakunns, P. 2009. “Job Disamenities, Job Satisfaction, Quit Intentions, and Actual Separations: Putting the Pieces Together." Industrial Relations 48: 73-96.

Borg, V. and Kristensen, T.S. 2000. "Social class and self-rated health: Can the gradient be explained by differences in life style or work environment?" Social Science and Medicine 51: 1019-1030.

Bratti, M. and Miranda, A. 2010. "Non pecuniary returns to higher education: the effect of smoking intensity in the UK." Health Economics 19: 906-920.

Breslow, L. 1999. "From disease prevention to health promotion." JAMA 281: 1030-1033.

Cappellari, L. and Jenkins, S. P. 2003. "Multivariate probit regression using simulated maximum likelihood." Stata Journal 3: 278-294.

Cappelli, P., Bassi, L., Katz, H., Knoke, D., Osterman, P.and Useem, M. 1997. Change at work. New York: Oxford University Press.

Contoyannis, P. and Jones, A. M. 2004. "Socio-economic status, health and lifestyle." Journal of Health Economics 23: 965-995.

Cottini, E. and Lucifora, C. 2013. "Mental Health and Working Conditions in European Countries.” Industrial and Labor Relations Review 66: 958-988. 
Cottini, E. 2012. "Health at work and Low pay: a European Perspective." The Manchester School 80: 75-98.

Cox, T., Griffiths, A. and Rial-González, E. 2000. Research on work-related stress. Luxembourg: European Agency for Safety and Health at Work.

Datta Gupta, N., Kristensen, N. 2007. "Work environment satisfaction and employee health: panel evidence from Denmark, France and Spain, 1994-2001." European Journal of Health Economics 9: 51-61.

Goldberg, D.P., Gater, T., Sartorious, N., Ustun, T.B., Piccinelli, M., Gureje, O. and Rutter, C. 1997. "The validity of two versions of the GHQ in the WHO study of mental illness in general health care." Psychological Medicine 27: 191-197.

Hellerstedt, W.L. \& Jeffery, R.W. 1997. "The association of job strain and health behaviours in men and women." International Journal of Epidemiology 26: 575-583.

Hu, T. W., Ren, Q. F., Keeler, T. and Bartlett, J. 1995. "The demand for cigarettes in California and behavioural risk factors." Health Economics 4: 7-14.

Idler, E. L. and Benyamini, Y. 1997. "Self-rated health and mortality: a review of twenty-seven community studies." Journal of Health and Social Behavior, 38: 21-37.

Jurges, H. 2007. "True health vs Response Style: exploring cross country differences in self-reported health." Health Economics 16: 163-178.

Karasek, R.A. 1979. "Job demands, job decision latitude, and mental strain: implications for job redesign." Administrative Science Quarterly 24: 285-308.

Karasek, R. and Theorell, T. 1990. Healthy work: stress, productivity, and the reconstruction of working life. New York: Basic Books.

Kenkel, D. 1995. "Should you eat breakfast? Estimates from health production functions." Health Economics 4: 5-29.

Greenberg, E.S. and Grunberg, L. 1995. "Work alienation and problem alcohol behavior." Journal of Health and Social Behavior 36: 83-102.

Grossman, M. 1972." On the concept of health capital and the demand for health." Journal of Polical Economy 80: 223-255.

Mully, J., Portney, P.R. 1990. "Air pollution, cigarette smoking, and the production of respiratory health." Journal of Health Economics 9: 193-205. 
Netterstrøm, B., Kristensen, T.S., Damsgaard, M.T., Olsen, O. and Sjol, A. 1991. "Job strain and cardiovascular risk factors: a cross sectional study of employed Danish men and women.” British Journal of Industrial Medicine 48: 684-689.

OECD 2008. “Are all Jobs Good for your Health? The Impact of Work Status and Working Conditions on Mental health.” OECD Employment Outlook, Paris: OECD.

Otten, F., Bosma, H. and Swinkels, H. 1999. "Job stress and smoking in the Dutch labour force." European Journal of Public Health 9: 58-61.

Parrott, A.C. 1999. "Does cigarette smoking cause stress?" The American Psychologist 54: 817-820.

Patja, K., Jousilahti, P., Hu, G. and Valle, T. 2005. "Effects of smoking, obesity and physical activity on the risk of type 2 diabetes in middle-aged Finnish men and women." Journal of Internal Medicine 258: 356-362.

Perkins, K.A. and Grobe, J.E. 1992. "Increased desire to smoke during acute stress." British Journal of Addiction 87: 1037-1040.

Robone, S., Jones, A.M. and Rice, N. 2011. "Contractual conditions, working conditions, health and well-being in the British Household Panel Survey." The European Journal of Health Economics 12: 429-444.

Siegrist, J. 1996. “Adverse Health Effects of High-Effort/Low-Reward Conditions.” Journal of Occupational Health Psychology 1: 27-41.

Siegrist, J. and Rödel, A. 2006. "Work stress and health risk behavior." Scandinavian Journal of Work, Environment \& Health 32: 473-481.

Stock, S.R., Fernandes, R., Delisle, A. and Vezina, N. 2005. "Reproducibility and validity of workers' self-reports of physical work demands." Scandinavian Journal of Work, Environment \& Health 31: 409-437.

Warburton, D. M. 1992. "Smoking within reason." Journal of Smoking Related Disorders 3: 55-59.

Wilde, J. 2000. "Identification of multiple equation probit models with endogenous dummy regressors.” Economic Letters 69: 309-312. 



\section{Working Paper del Dipartimento di Economia e Finanza}

1. L. Colombo, H. Dawid, Strategic Location Choice under Dynamic Oligopolistic Competition and Spillovers, novembre 2013.

2. M. Bordignon, M. Gamalerio, G. Turati, Decentralization, Vertical Fiscal Imbalance, and Political Selection, novembre 2013.

3. M. Guerini, Is the Friedman Rule Stabilizing? Some Unpleasant Results in a Heterogeneous Expectations Framework, novembre 2013.

4. E. Brenna, C. Di Novi, Is caring for elderly parents detrimental to women's mental health? The influence of the European North-South gradient, novembre 2013.

5. F. Sobbrio, Citizen-Editors' Endogenous Information Acquisition and News Accuracy, novembre 2013.

6. P. Bingley, L. Cappellari, Correlation of Brothers Earnings and Intergenerational Transmission, novembre 2013.

7. T. Assenza, W. A. Brock, C. H. Hommes, Animal Spirits, Heterogeneous Expectations and the Emergence of Booms and Busts, dicembre 2013.

8. D. Parisi, Is There Room for 'Fear' as a Human Passion in the Work by Adam Smith?, gennaio 2014

9. E. Brenna, F. Spandonaro, Does federalism induce patients' mobility across regions? Evidence from the Italian experience, febbraio 2014.

10. A. Monticini, F. Ravazzolo, Forecasting the intraday market price of money, febbraio 2014.

11. Tiziana Assenza, Jakob Grazzini, Cars Hommes, Domenico Massaro, PQ Strategies in Monopolistic Competition: Some Insights from the Lab, marzo 2014.

12. R. Davidson, A. Monticini, Heteroskedasticity-and-Autocorrelation-Consistent Bootstrapping, marzo 2014.

13. C. Lucifora, S. Moriconi, Policy Myopia and Labour Market Institutions, giugno 2014.

14. N. Pecora, A. Spelta, Shareholding Network in the Euro Area Banking Market, giugno 2014.

15. G. Mazzolini, The economic consequences of accidents at work, giugno 2014.

16. M. Ambrosanio, P. Balduzzi, M. Bordignon, Economic crisis and fiscal federalism in Italy, settembre 2014.

17. P. Bingley, L. Cappellari, K. Tatsiramos, Family, Community and Long-Term Earnings Inequality, ottobre 2014.

18. S. Frazzoni, M. L. Mancusi, Z. Rotondi, M. Sobrero, A. Vezzulli, Innovation and export in SMEs: the role of relationship banking, novembre 2014.

19. H. Gnutzmann, Price Discrimination in Asymmetric Industries: Implications for Competition and Welfare, novembre 2014.

20. A. Baglioni, A. Boitani, M. Bordignon, Labor mobility and fiscal policy in a currency union, novembre 2014.

21. C. Nielsen, Rational Overconfidence and Social Security, dicembre 2014.

22. M. Kurz, M. Motolese, G. Piccillo, H. Wu, Monetary Policy with Diverse Private Expectations, febbraio 2015.

23. S. Piccolo, P. Tedeschi, G. Ursino, How Limiting Deceptive Practices Harms Consumers, maggio 2015.

24. A.K.S. Chand, S. Currarini, G. Ursino, Cheap Talk with Correlated Signals, maggio 2015.

25. S. Piccolo, P. Tedeschi, G. Ursino, Deceptive Advertising with Rational Buyers, giugno 2015. 
26. S. Piccolo, E. Tarantino, G. Ursino, The Value of Transparency in Multidivisional Firms, giugno 2015.

27. G. Ursino, Supply Chain Control: a Theory of Vertical Integration, giugno 2015.

28. I. Aldasoro, D. Delli Gatti, E. Faia, Bank Networks: Contagion, Systemic Risk and Prudential Policy, luglio 2015.

29. S. Moriconi, G. Peri, Country-Specific Preferences and Employment Rates in Europe, settembre 2015.

30. R. Crinò, L. Ogliari, Financial Frictions, Product Quality, and International Trade, settembre 2015.

31. J. Grazzini, A. Spelta, An empirical analysis of the global input-output network and its evolution, ottobre 2015.

32. L. Cappellari, A. Di Paolo, Bilingual Schooling and Earnings: Evidence from a Languagein-Education Reform, novembre 2015.

33. A. Litina, S. Moriconi, S. Zanaj, The Cultural Transmission of Environmental Preferences: Evidence from International Migration, novembre 2015.

34. S. Moriconi, P. M. Picard, S. Zanaj, Commodity Taxation and Regulatory Competition, novembre 2015.

35. M. Bordignon, V. Grembi, S. Piazza, Who do you blame in local finance? An analysis of municipal financing in Italy, dicembre 2015.

36. A. Spelta, A unified view of systemic risk: detecting SIFIs and forecasting the financial cycle via EWSs, gennaio 2016.

37. N. Pecora, A. Spelta, Discovering SIFIs in interbank communities, febbraio 2016.

38. M. Botta, L. Colombo, Macroeconomic and Institutional Determinants of Capital Structure Decisions, aprile 2016.

39. A. Gamba, G. Immordino, S. Piccolo, Organized Crime and the Bright Side of Subversion of Law, maggio 2016.

40. L. Corno, N. Hildebrandt, A. Voena, Weather Shocks, Age of Marriage and the Direction of Marriage Payments, maggio 2016.

41. A. Spelta, Stock prices prediction via tensor decomposition and links forecast, maggio 2016.

42. T. Assenza, D. Delli Gatti, J. Grazzini, G. Ricchiuti, Heterogeneous Firms and International Trade: The role of productivity and financial fragility, giugno 2016.

43. S. Moriconi, Taxation, industry integration and production efficiency, giugno 2016.

44. L. Fiorito, C. Orsi, Survival Value and a Robust, Practical, Joyless Individualism: Thomas Nixon Carver, Social Justice, and Eugenics, luglio 2016.

45. E. Cottini, P. Ghinetti, Employment insecurity and employees' health in Denmark, settembre 2016.

46. G. Cecere, N. Corrocher, M. L. Mancusi, Financial constraints and public funding for ecoinnovation: Empirical evidence on European SMEs, settembre 2016.

47. E. Brenna, L. Gitto, Financing elderly care in Italy and Europe. Is there a common vision?, settembre 2016.

48. D. G. C. Britto, Unemployment Insurance and the Duration of Employment: Theory and Evidence from a Regression Kink Design, settembre 2016.

49. E. Caroli, C.Lucifora, D. Vigani, Is there a Retirement-Health Care utilization puzzle? Evidence from SHARE data in Europe, ottobre 2016.

50. G. Femminis, From simple growth to numerical simulations: A primer in dynamic programming, ottobre 2016.

51. C. Lucifora, M. Tonello, Monitoring and sanctioning cheating at school: What works? Evidence from a national evaluation program, ottobre 2016. 
52. A. Baglioni, M. Esposito, Modigliani-Miller Doesn't Hold in a "Bailinable” World: A New Capital Structure to Reduce the Banks' Funding Cost, novembre 2016.

53. L. Cappellari, P. Castelnovo, D. Checchi, M. Leonardi, Skilled or educated? Educational reforms, human capital and earnings, novembre 2016.

54. D. Britto, S. Fiorin, Corruption and Legislature Size: Evidence from Brazil, dicembre 2016.

55. F. Andreoli, E. Peluso, So close yet so unequal: Reconsidering spatial inequality in U.S. cities, febbraio 2017.

56. E. Cottini, P. Ghinetti, Is it the way you live or the job you have? Health effects of lifestyles and working conditions, marzo 2017. 